AperTO - Archivio Istituzionale Open Access dell'Università di Torino

\title{
Emotions and political unrest
}

\section{This is the author's manuscript}

Original Citation:

Availability:

This version is available http://hdl.handle.net/2318/1652475

since 2017-11-21T15:10:15Z

Published version:

DOI:10.1086/691700

Terms of use:

Open Access

Anyone can freely access the full text of works made available as "Open Access". Works made available under a Creative Commons license can be used according to the terms and conditions of said license. Use of all other works requires consent of the right holder (author or publisher) if not exempted from copyright protection by the applicable law. 


\title{
Emotions and Political Unrest*
}

\author{
Francesco Passarelli† and Guido Tabellini ${ }^{\ddagger}$
}

\begin{abstract}
How does political unrest influence public policy? We assume that protests are an emotional reaction to unfair treatment. Individuals have a consistent view of fairness, that internalizes government constraints. Individuals accept lower welfare if the government is more constrained. This resignation effect induces a benevolent government to delay unpleasant choices and accumulate public debt, to mitigate social unrest. More radical and homogenous groups are more prone to unrest, and hence more influential. Even if the government is benevolent and all groups are identical in their propensity to riot, equilibrium policy can be distorted. The evidence is consistent with these implications.
\end{abstract}

*We thank Jesse Shapiro, Alberto Alesina, Pierpaolo Battigalli, Roland Bénabou, Maristella Botticini, Stefano DellaVigna, Ruben Enikolopov, Nicola Gennaioli, Oliver Hart, Elhanan Helpman, Alessandro Lizzeri, Maria Petrova, Salvatore Piccolo, Giacomo Ponzetto, Kenneth Shepsle, Thierry Verdier, four anonymous referees and participants in seminars and conferences at the University of Amsterdam, Barcelona GSE, Berkeley, Bocconi, CIFAR, Dartmouth, Eief, EUI, Harvard, IMT (Lucca), LSE, NBER, Princeton IAS, PUC-Rio and Sciences Po for helpful comments, and Chiara Ferrero, Giampaolo Lecce and Luca Riva for excellent research assistance. We are also grateful to Alberto Alesina, Dorian Carloni and Giampaolo Lecce for making their data available. Financial support from ERC grant 230088 is gratefully acknowledged.

${ }^{\dagger}$ Università di Teramo; ISLA and Centro Baffi, Università Bocconi.

E-mail: francesco.passarelli@unibocconi.it

Web: http://uniteramo.academia.edu/FrancescoPassarelli

‡Department of Economics and IGIER, Università Bocconi; CEPR; CESifo; and CIFAR.

E-mail: guido.tabellini@unibocconi.it

Web: http://www.igier.unibocconi.it/tabellini 


\section{Introduction}

In September 2012, the government of Portugal introduced an ambitious plan to shift a fraction of social security contributions from employers to employees, to restore competitiveness of the Portuguese economy. In the subsequent days hundreds of thousands of workers took to the streets, and the government withdrew the proposal. A few months earlier, the Italian government had attempted to liberalize taxi licences. There too the proposed legislation was soon withdrawn, to interrupt protests by angry taxi drivers who blocked traffic in several Italian cities. ${ }^{1}$ These anecdotes suggest that political unrest is often a major force shaping public policy even in advanced democracies. Despite external constraints and unsustainable status quo, such as during the Euro area sovereign debt crisis, democratically elected governments enjoying broad legislative support bend to the opposition of street rioters. Yet, this channel of political influence is often neglected by the literature. Except for a few contributions, most political economics has focused on voting and lobbying, ignoring that protests and riots are often equally relevant forms of political participation in democracies. The main goal of this paper is to fill this gap, explaining how political unrest influences public policy and how this differs from voting and lobbying. ${ }^{2}$

Our starting point is the idea that political unrest is largely motivated by emotions, rather than by instrumental motives. Individuals participate in costly protests because they are aggrieved and feel unfairly treated. Other than in this emotional reaction, however, individuals are assumed to be rational.

Individuals behave rationally in two respects. First, they choose whether to participate in collective actions weighing the pros and cons. Participation provides a psychological reward to the individual, which is commensurate to the feeling of aggrievement, and which is traded off against other considerations. The net benefit of participation depends on how many other individuals also participate. Hence, a complementarity is at work: if expected participation is large, then more individuals are attracted to the protest for the same level of aggrievement. This complementarity amplifies the mass reaction to controversial policy decisions, and yields additional implications.

Second, individuals have a structured and rational view of what they are entitled to. A policy entitlement is a policy outcome that individuals expect on the ground of fairness. If the government violates these expectations of fair behavior, then individuals are aggrieved and react emotionally. The emotional reaction is predictable, however, because individual feelings

\footnotetext{
${ }^{1}$ On Portugal, see Financial Times, 9/26/2012. On Italy, see The Economist, 1/28/2012 and The New York Times, 3/1/2012.

${ }^{2}$ The literature on democratic transitions asks how the threat of violence influences the evolution of political institutions (e.g. Acemoglu and Robinson (2006a), Persson and Tabellini (2009)), without however paying much attention to the mechanisms that trigger participation. Lohman (1993) and Battaglini and Bénabou (2003) study costly political activism as signals of policy preferences.
} 
of aggrievement follow from a consistent and logical view of policy entitlements that also takes into account the government constraints. Thus, policy entitlements provide reference points for individuals' feelings of aggrievement. They are endogenously determined in equilibrium, and change with the external situation. In particular, if the government becomes more constrained, individuals take this into account and adjust their reference points accordingly.

In a dynamic framework, this has important implications. Individuals form their policy entitlements taking into account the current state of the world. If fewer policy options are available, then rational individuals scale back their expectations and accept a reduction in welfare that, in other circumstances, would have caused aggrievement and political unrest. Whenever this resignation effect is operative, it creates an incentive for the policymaker to delay unpleasant policy decisions or to constraint its future choice set. The reason is that these additional constraints force individuals to become less demanding, and this mitigates future social conflict.

Finally, we assume that there is a self-serving bias in moral judgements. Fairness is determined behind a veil of ignorance. But the veil is not thick enough to completely hide one's individual situation. Thus, policy entitlements are systematically tainted by selfish interests, as individuals at least partly conflate what is fair with what is convenient for them. This in turn implies that there is political conflict, as members of different economic or social groups have conflicting and mutually incompatible views of policy entitlements.

In order to focus on how political unrest influences policy decisions, we assume that no other political distortion is at work. Hence, policy is set by a benevolent government who strives to find an optimal compromise between possibly incompatible views of what is a fair policy, with the goal of reaching economic efficiency but also mitigating political unrest.

This general framework yields several novel insights. First, even if the government is benevolent and all groups in society are identical in their propensity to riot, equilibrium policy can be distorted. This contrasts with standard models of probabilistic voting and lobbying, where equilibrium policy is undistorted if all groups are equally represented in politics (cf. Persson and Tabellini 2000).

Second, and most novel, in a dynamic environment the threat of political unrest induces an intertemporal distortion in economic policy. The reason is the resignation effect described above: even a benevolent government finds it optimal to constrain its future decisions, in order to mitigate future unrest. Specifically, issuing government debt has two political benefits in this setting. First, it provides an additional instrument with which to dampen the current riots of the more demanding groups. Second, it makes all groups less demanding (and hence less prone to riot) tomorrow, because everyone is aware that the government has fewer resources available.

This result is consistent with empirical findings that, in a large sample of countries, debt 
accumulation is positively correlated with social instability (Woo 2003). Such correlation in the data has traditionally been interpreted as reflecting myopia induced by the risk of alternation in government, as in Alesina and Tabellini (1990). Here government instability is ruled out by assumption, however, and the intertemporal distortion reflects a farsighted attempt by a benevolent policymaker to mitigate social conflict.

Third, the framework uncovers additional sources of political influence. The more influential groups are those that can mobilize more easily. These are the more homogeneous groups, with stronger and more radical feelings of policy entitlements. We present evidence that participants in riots are politically engaged, strongly attached to specific parties and tend to be political extremists. Some of these features differ from those emphasized by probabilistic voting, where the influential groups are those with many "swing voters", i.e. centrist voters who are mobile across parties and who reward policy favors with their vote (e.g. Persson and Tabellini 2000). Thus, different channels of political participation confer influence to different groups. More radical and politically engaged groups are less likely to influence policy at the ballot, but more likely to do so in the streets.

We derive these results in a general theoretical framework, and then we illustrate the mechanisms at work in a simple model of redistribution. Political unrest leads to two distortions: an excessive amount of redistribution and an excessive accumulation of public debt. We also provide evidence consistent with some of these findings.

This paper is related to an extensive literature in several areas of social sciences. Ponticelli and Voth (2011) and Voth (2011) describe episodes of social unrest, with data going back to the prewar period and with a special focus on Europe and Latin America. They show that political unrest increases systematically during recessions and fiscal retrenchments. Similar results are obtained using the more detailed database constructed by Francisco (2006) for 28 European countries in 1980-1995. Francisco also records the issue that triggered each unrest episode, showing that unrest associated with fiscal policy draws many more people in the streets compared to other (perhaps more noble) political causes. ${ }^{3}$ We use some of these data to test some implications of our model in section 4 .

Our model of riot participation extends the framework pioneered by Granovetter (1978), who however stopped short of modeling riots as Nash equilibria. Diermeier (2012) takes a similar approach, but also does not study equilibrium behavior, focusing instead on a dynamic framework where citizens' participation in a boycott follows a behavioral rule. See also the pioneering work of Tullock (1971), who however rests on different assumptions about individual motivations.

The idea that aggrievement is caused by unfair treatment, and that individuals take costly

\footnotetext{
${ }^{3}$ The average protest associated with spending cuts in the database by Francisco (2006) sees the participation of almost 200,000 individuals, against an average of almost 6,000 participants for the environment, 20,000 for peace, and 50,000 for education (cf. Ponticelli and Voth 2011).
} 
actions to display aggrievement or take "revenge", is present in a number of recent economic studies. Hart and Moore (2008) point to the role of complete contracts as reference points that reduce costly misunderstanding within organizations, and Fehr et al. (2011) find experimental evidence supporting this idea. Rotemberg (2009) studies a model in which fairness as perceived by consumers acts as a constraint on pricing decisions by profit maximizing firms. All these models, like ours, belong to the class of psychological games studied by Geanakoplos et al. (1989), Battigalli and Dufwenberg (2009), Battigalli et al. (2015). ${ }^{4}$

In our model individuals have expectations about a fair policy and a corresponding level of entitled utility in every state of the world. Thus the fair policy is a reference point against which to assess actual policies. This ties our model to regret theory (Sugden 2003) and, in general, to the recent literature on endogenous and stochastic reference points (Shalev 2000, Koszegi and Rabin 2006). Like in some of these papers, our reference point is endogenous and it is part of the equilibrium. The precise definition of the reference point differs from that in the literature, however, because here it has a normative interpretation related to fairness. In this, our paper is close to Akerlof (1982), except that we emphasize negative (rather than positive) reciprocity.

Several papers have stressed the existence and implications of self-serving bias in moral judgments, and more generally in the formation of expectations of fair behavior (Babcock et al. 1995, Rabin 1995). In our model, self-serving bias affects all individuals of the same group. This common distortion affecting group members is a robust phenomenon in psychology. Early empirical studies are Hastorf and Cantril (1954), and Messick and Sentis (1979). ${ }^{5}$

The outline of the paper is as follows. Section 2 lays out the general theoretical framework in a static setting and illustrates the mechanisms at work in a simple example of redistribution. Section 3 extends the analysis to an intertemporal setting, both in general and in the model of redistribution, and illustrates how the resignation effect leads to the accumulation of public debt. Section 4 presents some evidence consistent with the general implications of the model. Section 5 concludes. An Appendix at the end of the paper contains some of the proofs. An Online Appendix contains additional details, data sources and variable definitions, and further empirical evidence.

\footnotetext{
${ }^{4} \mathrm{~A}$ large empirical literature in psychology argues that perceived unfairness is a major instigator of anger and violence (cf. Berkowitz and Harmon Jones 2004). These ideas have been used by social psychologists to explain social movements as emotional phenomena (cf. Gould 2004, Jasper 1997, and the relative-deprivation theory by Gurr 1970).

${ }^{5}$ Our paper is also closely related to the rapidly growing literature on how endogenous values or beliefs shape the strategic behavior of agents in a variety of economic and political circumstances (Bénabou and Tirole 2009, Brunnermeier and Parker 2005, Tabellini 2008). The details and specific implications of those models are quite different from those emphasized in this paper.
} 


\section{$2 \quad$ A static model}

The economy consists of $N$ groups indexed by $i$, of size $1>\lambda^{i}>0$ with $\sum_{i=1}^{N} \lambda^{i}=1$. Individuals in group $i$ have the same policy preferences, represented by the indirect utility function $V^{i}(q)$, where $q \in R$ is the policy and $V^{i}($.$) a continuously differentiable and concave$ function. Throughout we assume that $V^{i}(q)$ is bounded from above and non-negative for any $q$ (alternatively we could assume that the policy space is bounded).

As described below, each individual unilaterally decides whether to participate in political unrest (henceforth riots) with other members of the same group. Denote with $p^{i}$ the participation rate in riots within group $i$. In the next subsection we derive the equilibrium participation rate and show that it can be expressed as a function of the policy, $p^{i}=P^{i}(q)$.

Riots cause social harm, and the government trades off the social welfare effects of the policy against the social harm inflicted by riots. Specifically, let

$$
W(q)=\sum_{i=1}^{N} \lambda^{i} V^{i}(q)
$$

be the standard Benthamite social welfare function. The government sets policy to maximize

$$
W(q)-\sum_{i=1}^{n} \lambda^{i} \varsigma^{i} P^{i}(q)
$$

The second term in (2) implies that the welfare loss due to riots is proportional to how many people are involved. The parameter $\varsigma^{i} \geq 0$ captures how harmful riots by group $i$ are. A literal interpretation of $(2)$ is that the government is benevolent and riots inflict a material loss of social welfare. ${ }^{6}$ The probability $P^{i}($.$) can also be interpreted as the risk that a critical$ threshold is reached, beyond which something costly happens, such as a deep political crisis. Yet another interpretation is that the government is opportunistic or politically motivated, and riots hinder the pursuit of political objectives. ${ }^{7}$

\footnotetext{
${ }^{6}$ Collins and Margo (2007) studied labor and housing markets in US urban areas most involved by the black riots in the sixties. They found that between 1960 and 1980 black-owned property declined in value by about $14 \%$ in those areas compared to others. The average growth in median black family income was approximately $8 \%-12 \%$ lower, and adult males' employment also showed sign of decline. DiPasquale and Glaeser (1999) documented that the L.A. riots in 1992 resulted in 52 deaths, 2, 500 injuries and at least $\$ 446$ million in property damages.

${ }^{7}$ Implicit in the interpretation of a benevolent government is the view that the government internalizes the welfare effect of the policy (as captured by $W($.$) ) and the social disruptions caused by riots, but it does not$ give extra weight to the psychological costs (or aggrievements) that induce citizens to protest.
} 


\subsection{A simple model of riots}

Our formulation in this subsection draws on Granovetter (1978). Individuals unilaterally decide whether to participate in a riot, trading off the costs and benefits. The benefit is purely emotional: it is the psychological reward of joining other group members in a public display of the frustration caused by the policy, or of contributing to take a revenge on an unfair government.

We refer to the psychological benefit of rioting, denoted $a^{i}$, as the aggrievement caused by the policy to members of group $i$, because we assume that this benefit is related to the emotion of being the victim of unfair treatment. The next subsection derives individual aggrievements from an explicit formulation of individual expectations of what is a fair policy. For now all we need is that $a^{i} \in\left[0, \bar{a}^{i}\right]$. The upper bound $\bar{a}^{i}$ is derived below in footnote 10 .

Joining a riot also entails costs, in terms of time, or risk of being arrested or injured. We model these costs as the sum of two components: $\mu+\varepsilon^{i j}$. The parameter $\mu>0$ is known and common to all, and reflects external conditions such as the risk of violent repression. The term $\varepsilon^{i j}$ is a random variable that captures idiosyncratic components of the cost or benefit of participation (the superscript $i j$ refers to individual $j$ in group $i$ ), and is uniformly distributed with mean 0 and density $1 / 2 \sigma^{i}$ within each group $i$.

Finally, we assume that there is a complementarity: the benefit of participation grows proportionately with the number of other group members also participating in the riot, $p^{i} \lambda^{i}$. As explained below, aggrievement is an individual emotion, but it is related to the feeling that the group is treated unfairly. Hence, the psychological benefit of a public display of anger is stronger if the emotion is more widely shared. Participation could also proxy for the probability of reaching a critical threshold that triggers a political crisis; in this interpretation, the complementarity reflects the feeling of contributing to a more meaningful event with a greater chance of success. Equivalently the complementarity could also be on the cost side: the probability of being arrested is smaller in a larger crowd. ${ }^{8}$

Combining these assumptions, individual $j$ in group $i$ chooses to riot if benefits are larger than costs:

$$
p^{i} \lambda^{i} a^{i}-\mu-\varepsilon^{i j} \geq 0
$$

or equivalently, if $\varepsilon^{i j} \leq p^{i} \lambda^{i} a^{i}-\mu$. This occurs with probability

$$
p^{i}=\operatorname{Pr}\left(\varepsilon^{i j} \leq p^{i} \lambda^{i} a^{i}-\mu\right)=\frac{1}{2}+\frac{p^{i} \lambda^{i} a^{i}-\mu}{2 \sigma^{i}}
$$

where the second equality follows from our assumption of a uniform distribution. Solving (3)

\footnotetext{
${ }^{8}$ This formulation neglects possible strategic interactions between groups: if the policy opposed by group $i$ is advocated by other groups (or viceversa), a wider participation in other groups could influence my willingness to riot, because it might affect the probability of success of the collective action, or my feeling of group identity.
} 
for $p^{i}$ we then obtain the equilibrium participation rate as a function of group aggrievement:

$$
p^{* i}=\frac{\sigma^{i}-\mu}{2 \sigma^{i}-\lambda^{i} a^{i}}
$$

To insure that $1>p^{* i}>0$, we assume that $\sigma^{i}>\operatorname{Max}\left[\mu, \lambda^{i} \bar{a}^{i}-\mu\right]$ for all $i$, where $\bar{a}^{i}>0$ is the upper bound on $a^{i}$ introduced above (see also footnote 10 below). This also implies that $\partial p^{* i} / \partial a^{i}>0$, namely participation is higher if the group is more aggrieved.

The derivative $\partial p^{* i} / \partial a^{i}$ is larger (and hence participation is more sensitive to aggrievement) if $a^{i}$ and $\lambda^{i}$ are large, and if $\sigma^{i}$ is small. This reflects the interaction of complementarity and heterogeneity. If an agent knows that more people are involved, he/she draws a stronger net benefit from participation. Thus, participation reacts to aggrievement at an increasing rate, and large (high $\lambda^{i}$ ) groups riot more often. Moreover, riots are more sensitive to aggrievement in more homogeneous (low $\sigma^{i}$ ) groups, because more people are sucked into participation at the margin if the density $1 / 2 \sigma^{i}$ is higher. The prediction on group size is the opposite of Olson (1965), who suggests that smaller groups find it easier to overcome the collective action

problem because they can more easily monitor compliance. The evidence suggests that indeed riots tend to occur in larger groups (Ponticelli and Voth 2011, Koopmans 1993).

\subsection{Entitlements and aggrievement}

This subsection derives the aggrievements $a^{i}$ from individual expectations of a fair policy. Each group member feels entitled to a level of welfare corresponding to a fair policy. Individuals are aggrieved if actual welfare falls short of their expected entitlements. Entitlements are not arbitrary: they are derived from an internally consistent view of the world, although they are tainted by self-serving bias.

Let $\hat{q}^{i}$ be the policy deemed fair by group $i$ (henceforth the "subjectively fair" policy). We assume that $\hat{q}^{i}$ is derived from a modified social welfare optimization, where group $i$ is over-represented relative to the social optimum. In other words, each individual thinks that his/her position in society is more typical than it actually is. Thus, subjectively fair policies are computed behind a distorted veil of ignorance. Specifically $\hat{q}^{i}$ maximizes a distorted welfare function $W^{i}(q)$ defined as $W($.$) in (1), except that group i$ receives weight $\pi^{i i}=\lambda^{i}\left(1+\delta^{i}\right)$, while all other groups $\kappa \neq i$ receive weight $\pi^{i k}=\lambda^{k}\left(1-\delta^{i}\right)$ :

$$
W^{i}(q)=\sum_{k} \pi^{i k} V^{k}(q)
$$

The parameter $\delta^{i} \in(0,1)$ captures the self-serving bias of group $i$, or possibly other ideological dispositions which lead people to think that their vision of the world is the right one. The subjectively fair policy implies a reference (or entitled) utility, $R^{i}=V^{i}\left(\hat{q}^{i}\right)$, namely an expected 
level of welfare for group $i$ that is deemed fair by members of that group.

Individuals feel aggrieved if and only if their actual welfare is below $R^{i}$, and aggrievement increases in their sense of deprivation. Specifically, for $\omega^{i}>0:^{9}$

$$
a^{i}=\frac{\omega^{i}}{2} \operatorname{Max}\left[0, R^{i}-V^{i}(q)\right]^{2} \equiv A^{i}(q)
$$

Note that, if at least one group in society is distorted by self-serving bias (if $\delta^{i}>0$ for some $i$ ), then entitlements cannot be mutually consistent. If so, some political conflict is unavoidable, and the threat of unrest is a relevant constraint. Note also that, in computing fair policies, individuals neglect the riots that may be triggered by such policies. Thus reference utilities are based on policies that are deemed fair, but not necessarily politically feasible.

By the results of the previous subsection, we obtain an expression for equilibrium participation in riots, as a function of government policy $q$, namely: ${ }^{10}$

$$
p^{* i}=\frac{\sigma^{i}-\mu}{2 \sigma^{i}-\lambda^{i} A^{i}(q)} \equiv P^{i}(q)
$$

Thus, policy affects riot participation through its effects on aggrievement. Specifically, if group $i$ is aggrieved, then:

$$
\begin{aligned}
P_{q}^{i}(q) & =\frac{\lambda^{i}}{\sigma^{i}-\mu}\left[P^{i}(q)\right]^{2} A_{q}^{i}(q) \\
& =-\frac{\lambda^{i}}{\sigma^{i}-\mu}\left[P^{i}(q)\right]^{2} \omega^{i}\left(R^{i}-V^{i}(q)\right) V_{q}^{i}
\end{aligned}
$$

By (6), as the policy becomes more favorable to that group (i.e. if $V_{q}^{i}>0$ ), aggrievement is reduced $\left(A_{q}^{i}(q)<0\right)$. This in turn entails lower riot incidence. Therefore, $P_{q}^{i}<0$ if the policy becomes more favorable to an aggrieved group.

\subsection{Equilibrium}

We are now ready to define and characterize the equilibrium.

Definition 1 An equilibrium consists of a vector of subjectively fair policies, $\left\{\hat{q}^{i}\right\}$, and corresponding reference utilities, $\left\{R^{i}\right\}$, a vector of participation rates, $\left\{p^{* i}\right\}$, and a policy $q^{*}$, such

\footnotetext{
${ }^{9}$ The results go through with a general convex function, including a piecewise linear aggrievement function. See the Online Appendix.

${ }^{10}$ Since we assumed that $V^{i}($.$) is non negative and bounded from above, the upper bound on aggrievements$ introduced above is: $\bar{a}^{i}=\frac{\omega^{i}}{2}\left(R^{i}\right)^{2}$. Thus, to make sure that $p^{* i}$ lies between 0 and 1 we need to assume that $\sigma^{i}>\operatorname{Max}\left[\mu, \lambda^{i} \frac{\omega^{i}}{2}\left(R^{i}\right)^{2}-\mu\right]$ for all $i$. Clearly, for any $\sigma^{i}, \lambda^{i}$ and $R^{i}$ there is always a value of $\omega^{i}$ satisfying this condition.
} 
that:

i) Fair policies maximize the modified social welfare functions of each group, (5).

ii) Within each group $i$, all members optimally choose whether to participate in the riot, given the equilibrium policy $q^{*}$, the group's reference utility $R^{i}$, and the equilibrium participation of other group members, $p^{* i}$.

iii) Government policy maximizes the social welfare function inclusive of riot costs (2), taking as given the groups' reference utilities $\left\{R^{i}\right\}$, and taking into account how the policy affects equilibrium participation through (7).

The equilibrium policy maximizes (2), yielding the first order condition:

$$
W_{q}\left(q^{*}\right)=\sum_{i} \lambda^{i} \varsigma^{i} P_{q}^{i}\left(q^{*}\right)
$$

Thus, a benevolent government trades off the direct welfare effects of the policy, $W_{q}$, against the disruptions caused by riots. By (1) and (8), the optimality condition can be rewritten as:

$$
\sum_{i} \lambda^{i}\left[1+\varsigma^{i} \Phi^{i}\left(q^{*}\right)\right] V_{q}^{i}\left(q^{*}\right)=0
$$

where $\Phi^{i}(q)=\lambda^{i}\left[P^{i}(q)\right]^{2} \omega^{i}\left(R^{i}-V^{i}(q)\right) /\left(\sigma^{i}-\mu\right)>0$ if group $i$ is aggrieved, and $\Phi^{i}=$ 0 otherwise. Equation (10) provides a full characterization of the equilibrium policy (the Appendix verifies that the second order conditions are satisfied because, given concavity of $V^{i}(q)$, the function $P^{i}(q)$ is convex, implying that the government objective function (2) is concave).

We summarize the results so far in the following:

Proposition 1 The equilibrium policy solves a modified social planner problem, where each group $i$ receives the extra weight $\varsigma^{i} \Phi^{i}\left(q^{*}\right) \geq 0$.

This equilibrium can be contrasted with other related models where political participation occurs through lobbying or voting, rather than protests. In these settings too, the equilibrium solves a modified social planner's problem, where group weights reflect their political influence. But here the implications and the drivers of group influence are different.

Let $q^{0}=\arg \max _{q} W(q)$ be the economically efficient policy that would be chosen by a benevolent social planner in the absence of any political constraints. Clearly, if the weights $\varsigma^{i} \Phi^{i}(q)$ were the same for all groups at the point $q^{0}$, then the equilibrium policy would also be economically efficient, i.e. $q^{*}=q^{0}$. In this case, the threat of riots would induce no policy distortions. Political unrest would still take place, and this would entail some loss of welfare. But the government would choose the economically efficient policy. If instead the weights $\varsigma^{i} \Phi^{i}(q)$ evaluated at the efficient policy $q^{0}$ differ across groups, then the threat of political unrest also induces policy distortions, and $q^{*} \neq q^{0}$. 
Only aggrieved groups receive extra weight and exert some policy influence. This can be seen by noting that $\Phi^{i}=0$ if the group is not aggrieved at the equilibrium policy. This result has an important implication. Contrary to existing models of probabilistic voting or lobbying, the equilibrium policy can be distorted $\left(q^{*} \neq q^{0}\right)$, even if all groups have access to the same participation technology. Specifically, suppose that all groups have the same parameters $\varsigma^{i}$, $\sigma^{i}, \delta^{i}, \omega^{i}$ defined above. Suppose however that, for some group $k$, the indirect utility function $V^{k}$ is maximized at the efficient policy, $q^{0}$. That group would be not aggrieved at $q=q^{0}$, and its weight $\varsigma^{k} \Phi^{k}(q)$ would be zero at $q^{0}$. But then, the government would find it optimal to deviate from the efficient policy, in order to mitigate the riots of other groups. Hence the efficient policy $q^{0}$ cannot be an equilibrium. This does not happen under probabilistic voting or lobbying, because there the extra weight received by each group does not vary with the policy $q$. The next subsection illustrates this result with an example.

More generally, the political influence of a group reflects the following features. First, more homogeneous (low $\sigma^{i}$ ) and larger (high $\lambda^{i}$ ) groups are better able to mobilize their members, and thus more influential. This differs from models of lobbying, where it is generally argued that smaller groups can more easily overcome the free rider problem, and homogeneity plays no role. Second, a more pronounced self-serving bias (high $\delta^{i}$ ) and a stronger sense of entitlements (high $\omega^{i}$ ) implies that group members are more easily aggrieved, and hence easier to mobilize and more responsive to policy changes. In other words, more radical and uncompromising groups are more threatening and hence influential. This differs from models of probabilistic voting, where instead the more influential groups have more ideologically neutral citizens, who are ready to vote for whoever provides policy favors. Third, groups whose protests have more destructive effects on society (i.e. with larger $\varsigma^{i}$ ), such as truck or taxi drivers, receive more favorable treatment.

Some of these predictions are consistent with the evidence from earlier studies. For instance, Bates (1981) claims that African governments favor urban workers at the expenses of rural producers, with policies that reduce the cost of food. His reasoning is consistent with our results: political unrest is much more threatening in urban areas, where mobilization is easier. Section 4 discusses other supporting evidence from opinion polls.

\subsection{Redistribution}

This subsection illustrates the political forces described above with a specific example. We show how the threat of political unrest shapes the design of welfare programs, resulting in an excessive amount of redistribution. This also introduces a simple model that will be extended to study intertemporal policies in the next section. 
A simple model of redistribution The economy consists of two equally sized groups $\left(\lambda^{i}=\right.$ $1 / 2$ ), indexed by $i=r, p$, the rich and the poor. Both have linear utility from consumption. The rich have an exogenous income of unity and pay a tax $\tau$. The poor have no work opportunities and receive a subsidy $s$ from the government. We capture the deadweight loss of taxation by means of the function $F(\tau)=\tau^{2} / 2 \alpha$, where the parameter $\alpha$ measures the inefficiency of taxation. Thus, the subsidy paid to the poor is $s=\tau-F(\tau)$, and we can write the indirect utility function of rich and poor individuals respectively as ${ }^{11}$ :

$$
V^{r}(\tau)=1-\tau, \quad V^{p}(\tau)=\tau-\tau^{2} / 2 \alpha
$$

and aggregate economic welfare, $W(\tau)$, as:

$$
W(\tau) \equiv \frac{1}{2} V^{r}(\tau)+\frac{1}{2} V^{p}(\tau)=\frac{1}{2}\left[1-\tau^{2} / 2 \alpha\right]
$$

In the absence of any political constraints, the efficient policy minimizes tax distortions and sets $\tau^{0}=s^{0}=0$. Of course, this is an artifact of the assumed linear utilities. Together with the assumption of a benevolent government, it allows us to abstract from any reason to make transfers, other than the curbing of political unrest.

The timing of events and the equilibrium are as described in the previous subsection. Individuals form expectations of fair policies $\hat{\tau}^{i}$ and form the corresponding reference utilities $R^{i}$. The government then sets policy $\tau$ and individuals choose whether to riot. To simplify notation, we assume that the two groups are identical in the parameters that concern riot participation, such as the social disruptions caused by the riots, $\varsigma$, the self-serving bias, $\delta$, the sensitivity of aggrievements, $\omega$, and the density parameter $\sigma$.

Fair policies To form expectations about the fair policy, $\hat{\tau}^{i}$, individuals maximize:

$$
W^{i}(\tau) \equiv \pi^{i r} \cdot(1-\tau)+\pi^{i p} \cdot\left(\tau-\tau^{2} / 2 \alpha\right), \quad i=r, p
$$

where $\pi^{i k}=\frac{1}{2}(1+\delta)$ if $i=k$, and $\pi^{i k}=\frac{1}{2}(1-\delta)$ if $i \neq k(i, k=r, p)$. Taking the first order condition of (13) with respect to $\tau$ for $i=r, p$, we get:

$$
-\pi^{i r}+\pi^{i p}(1-\tau / \alpha) \leq 0
$$

with strict inequality implying $\hat{\tau}^{i}=0$. Since $\pi^{r r}>\pi^{r p}$, for $i=r$ inequality (14) is always strict and $\hat{\tau}^{r}=0$. Thus, the rich want zero taxes. Next, consider $i=p$. Since $\pi^{p r}>\pi^{p p}$, now

\footnotetext{
${ }^{11}$ Thus, $V^{i}(\tau)$ are concave (strictly concave for $i=p$ ). Repeating the steps in Appendix (cf. proof of Proposition 1), the second order conditions of the government optimization problems are satisfied throughout this subsection.
} 
(14) holds with equality and simplifying we obtain $\hat{\tau}^{p}=2 \delta \alpha /(1+\delta)$. Thus, if the poor have at least some self-serving bias (if $\delta>0$ ), then $\hat{\tau}^{p}>0$. And if their self-serving bias is maximal (if $\delta=1)$, then their fair tax rate maximizes tax revenue $\left(\hat{\tau}^{p}=\alpha\right)$.

This result is very intuitive. Recall that the efficient policy entails no subsidies for the poor. A fortiori, this is also the policy deemed fair by the rich, given that their weight on the poor is smaller than for a utilitarian social planner. Moreover, at $\tau=0$ there are no distortions. Hence, even an infinitesimal self-serving bias induces the poor to demand some redistribution. As $\delta$ rises, the weight on the poor in the modified welfare function increases, and so does their fair tax rate.

Aggrievements and riots Equilibrium riots are obtained as in the previous subsection, through a series of steps. First, the subjectively fair policies imply corresponding reference utilities for both groups, $R^{i}$. Second, aggrievements $a^{i}=A^{i}(\tau)$ are obtained, as a function of the difference between reference and actual utilities, as in (6). By (4), $P^{i}(\tau)$ then has the following properties:

Lemma $1 P_{\tau}^{p} \leq 0 \leq P_{\tau}^{r}$, with strict inequality if and only if group $i$ is aggrieved (i.e. if and only if $\tau<\hat{\tau}^{p}$ and $\tau>\hat{\tau}^{r}$ respectively).

Proof. By $(8), P_{\tau}^{i}(\tau)$ has the same sign as $A_{\tau}^{i}(\tau)$. Differentiating (6) and (11) in the range of $\tau$ for which $i$ is aggrieved:

$$
A_{\tau}^{r}(\tau)=\omega\left(R^{r}-V^{r}(\tau)\right) \geq 0, \quad A_{\tau}^{p}(\tau)=-\omega\left(R^{p}-V^{p}(\tau)\right)(\alpha-\tau) / \alpha \leq 0
$$

with strict inequality if and only if $i$ is aggrieved (i.e. iff $\left.R^{i}>V^{i}\right) .{ }^{12}$

Quite intuitively, the poor are aggrieved if they do not get the positive subsidy they feel entitled to. Conversely, the rich feel aggrieved if taxes are raised above 0. As $\tau$ rises, aggrievement and riot participation decrease amongst the poor and increase amongst the rich.

Equilibrium policy We are now ready to describe the equilibrium. The government maximizes social welfare inclusive of the social cost of riots, $W(\tau)-\frac{\varsigma}{2}\left[P^{p}(\tau)+P^{r}(\tau)\right]$, where $W(\tau)=\frac{1}{2}\left[1-\tau^{2} / 2 \alpha\right]$ by $(12)$ and $P^{i}(\tau)$ is defined in (4), with $\lambda^{i}=1 / 2$. The optimality condition is:

$$
\tau=-\alpha \varsigma\left[P_{\tau}^{p}(\tau)+P_{\tau}^{r}(\tau)\right]
$$

Thus, the government trades off tax distortions against riot mitigation. Equation (16) implicitly defines the equilibrium tax rate, $\tau^{*}$. We have (see the Appendix for a complete proof):

\footnotetext{
${ }^{12}$ We only consider $\tau$ in the range $\tau \leq \alpha$, because $\tau=\alpha$ corresponds to the revenue maximizing tax rate.
} 
Proposition 2 In equilibrium $\hat{\tau}^{p}>\tau^{*}>0$ and the poor protest more than the rich: $p^{* p}>p^{* r}$.

The first statement follows from the fact that in equilibrium both groups must be aggrieved. To see this, note that at the efficient policy $\left(\tau^{0}=s^{0}=0\right)$ only the poor are aggrieved. Lemma 1 then implies that $P_{\tau}^{r}=0$ and $P_{\tau}^{p}<0$. Thus, at $\tau=0$ the RHS of (16) is positive but the LHS is 0 , violating the government optimality condition. At $\tau=0$ the government finds it optimal to raise taxes above zero and provide a positive subsidy, until the marginal tax distortions are just offset by the mitigation of riots by the poor (net of the increase in riots by the rich). By a similar argument $\tau=\hat{\tau}^{p}$ cannot be an equilibrium, since in this case the LHS of (16) would be positive, and the RHS would be negative by Lemma 1 . Thus $0<\tau^{*}<\hat{\tau}^{p}$ and in equilibrium both groups are aggrieved. Note that by assumption all groups have access to the same technology for political participation and are identical in all political respects. And yet, the equilibrium policy is distorted away from economic efficiency.

Despite the positive equilibrium tax rate, the poor protest more than the rich. This again follows from (16). Since the RHS of (16) is positive, by Lemma 1 it must be that $\left|P_{\tau}^{p}\right|>P_{\tau}^{r}$, which in turn (as shown in the Appendix) implies $p^{* p}>p^{* r}$. Intuitively, mitigating political unrest by the poor is costly in terms of tax distortions, and so the government stops short of equating marginal aggrievement across the two groups. Although perhaps not too surprising, this result is consistent with the evidence discussed below.

Finally, and as pointed out in the previous subsection, the equilibrium policy also depends on the parameters that describe the participation technology. At an interior optimum, anything that increases the threat of political unrest by the poor also induces the government to raise taxes and subsidies, and vice versa if unrest by the rich becomes more threatening. In particular, suppose that we vary these parameters separately for the rich and poor sectors. At an interior optimum, equilibrium taxes and subsidies increase with the degree of self-serving bias of the poor $\left(\delta^{p}\right)$, with the sensitivity of their aggrievement to deprivation $\left(\omega^{p}\right)$, with the disruptions caused by their riots $\left(\varsigma^{p}\right)$, and with the homogeneity of their group as captured by the inverse of the parameter $\sigma^{p}$. The reverse applies as we vary the corresponding parameters of the rich (with the exception of $\delta^{r}$, which has no effect on the equilibrium policy). The Online Appendix presents comparative statics formally.

\section{Dynamics}

In a dynamic economy with more than one period, this framework yields important additional implications. The reason is that any endogenous state variable such as public debt or aggregate capital can affect actual as well as reference utilities. In particular, groups can become resigned or entrenched depending on how the state variable affects their entitlements. These dynamic 
effects in turn shape the policymaker's intertemporal incentives, and can give rise to seemingly myopic policies.

\subsection{The general framework}

This subsection presents the general framework and defines the equilibrium. The characterization of the equilibrium is derived in the next subsection, in the context of the previous example of redistribution.

There are two periods, $t=1,2$. Let $V_{t}^{i}\left(q_{t}, b\right)$ denote group $i$ indirect utility in period $t$, where the notation is as before, and $b$ is an endogenous state variable set by the government in period 1, like public debt or public investment. Thus, $b$ is a policy variable in period 1 , but it is predetermined in period 2. There is no discounting and all individuals live two periods. Thus, at the beginning of period 1 expected lifetime utility for a member of group $i$ is $V_{1}^{i}\left(q_{1}, b\right)+V_{2}^{i}\left(q_{2}, b\right)$.

As before, the government trades off the direct welfare effects of the policies against their impact on political unrest. Thus, the government sets policy $\left\{q_{1}, b, q_{2}\right\}$ to maximize:

$$
\sum_{t} W_{t}\left(q_{t}, b\right)-\sum_{t} \sum_{i} \lambda^{i} \varsigma^{i} P_{t}^{i}\left(q_{t}, b\right)
$$

where $W_{t}=\sum_{i} \lambda^{i} V_{t}^{i}\left(q_{t}, b\right)$ captures the direct welfare effects of the policies.

The model is otherwise identical to the one described above, except that here all decisions are taken sequentially over time. Specifically, in each period:

- Individuals form expectations of what is a fair policy for the current period. These subjectively fair policies determine the corresponding reference utilities for the current period.

- The government sets actual policies.

- Individual aggrievements are determined, and individuals decide whether to riot.

Individuals fully take into account all information that is available at each node of the game. In each period fair policies maximize expected residual lifetime utility from that period onwards, behind the usual distorted veil of ignorance. Aggrievements are forward looking and correctly take into account equilibrium outcomes in subsequent periods.

Specifically, in period 2 the fair policy for group $i, \hat{q}_{2}^{i}=Q^{i}(b)$ maximizes:

$$
W_{2}^{i}\left(q_{2}, b\right)=\sum_{k=1}^{N} \pi^{i k} V_{2}^{k}\left(q_{2}, b\right)
$$

where as above the weights $\pi^{i k}$ capture $i$ 's distorted sense of fairness: $\pi^{i k}=\lambda^{k}\left(1+\delta^{i}\right)$ if $\kappa=i$, and $\pi^{i k}=\lambda^{k}\left(1-\delta^{i}\right)$ if $\kappa \neq i$. Note that in period 2 the state variable $b$ is predetermined and is taken as given when forming subjectively fair policies $\hat{q}_{2}^{i}$. 
In period 1 , instead, $b$ is treated as a policy variable. Thus individuals compute the fair policies $\hat{q}_{1}^{i}$ and $\hat{b}^{i}$, maximizing the following modified social welfare function:

$$
W_{1}^{i}\left(q_{1}, b\right)+W_{2}^{i}\left(Q^{i}(b), b\right)=\sum_{k=1}^{N} \pi^{i k} V_{1}^{k}\left(q_{1}, b\right)+\sum_{k=1}^{N} \pi^{i k} V_{2}^{k}\left[Q^{i}(b), b\right]
$$

The right hand side of (19) is a weighted average of residual expected lifetime utilities, with weights that reflect the self-serving bias $\delta^{i}$. Note that each $V_{2}^{k}($.$) incorporates the rational$ expectation of the future fair policy from the perspective of group $i$ as a function of $b$ : $\hat{q}_{2}^{i}=$ $Q^{i}(b)$. That is, when computing the fair value of the state variable $b$, each individual solves a dynamic programming problem and correctly takes into account how $b$ will change what he will deem fair in period 2.

As in the static model, these subjectively fair policies imply corresponding reference residual lifetime utilities (denoted with $R_{t}^{i}$ ) in each period:

$$
\begin{aligned}
R_{1}^{i} & =V_{1}^{i}\left(\hat{q}_{1}^{i}, \hat{b}^{i}\right)+V_{2}^{i}\left(Q^{i}\left(\hat{b}^{i}\right), \hat{b}^{i}\right) \\
R_{2}^{i}(b) & =V_{2}^{i}\left(Q^{i}(b), b\right)
\end{aligned}
$$

Note that period 2 reference utility depends on the state variable $b$, because $b$ is taken as given when expectations of the fair policy $\hat{q}_{2}^{i}$ are formed. The sign of the derivative $R_{2 b}^{i}(b)=$ $V_{2 q}^{i} Q_{b}^{i}+V_{2 b}^{i}$ plays an important role in the analysis below. If $R_{2 b}^{i}<0$, accumulation of the state variable $b$ reduces period 2 reference utility, making individuals in group $i$ willing to accept a lower level of welfare without feeling aggrieved (and vice versa if $R_{2 b}^{i}>0$ ). For this reason, we refer to $R_{2 b}^{i}<0$ as a "resignation effect".

If actual utilities fall short of these reference points, then individuals are aggrieved, as in the static model. Thus aggrievements in periods 1 and 2 respectively are:

$$
\begin{aligned}
& A_{1}^{i}\left(q_{1}, b\right)=\frac{\omega^{i}}{2} \operatorname{Max}\left[0, R_{1}^{i}-V_{1}^{i}\left(q_{1}, b\right)-V_{2}^{i}(G(b), b)\right]^{2} \\
& A_{2}^{i}\left(q_{2}, b\right)=\frac{\omega^{i}}{2} \operatorname{Max}\left[0, R_{2}^{i}(b)-V_{2}^{i}\left(q_{2}, b\right)\right]^{2}
\end{aligned}
$$

Several things are worth noting here. (i) Individuals are forward looking, and their aggrievement takes into account both current and future expected welfare relative to their reference point. Thus, a policy (such as government borrowing) that increases current welfare but reduces future welfare can still cause aggrievement in period 1 if it reduces overall expected utility below $R_{1}^{i}$. (ii) In evaluating future expected welfare, individuals correctly take into account all future implications of current policy choices along the equilibrium path. In particular, in period 1 they correctly anticipate that future equilibrium policies will respond to $b$ 
(through $q_{2}^{*}=G(b)$ ). Thus, in period 1 they are aggrieved if they observe an intertemporal policy that will bring about a loss of welfare in the equilibrium of period 2. (iii) As noted above, the endogenous predetermined variable $b$ affects period 2 aggrievements through both reference and actual utility. Thus, it is entirely possible that in period 2 individuals will not be aggrieved by a loss of welfare due to the state variable $b$, if this welfare loss was deemed unavoidable and also reduced their reference utility - this is the resignation effect noted above. Of course, the anticipation of a future welfare loss would cause aggrievement in period 1, as captured by the last term on the RHS of (22).

Finally, in each period $t$, riot participation is determined exactly as in the static model, based on current aggrievements, yielding an equilibrium participation rate that can be expressed as $p_{t}^{* i}=P_{t}^{i}\left(q_{t}, b\right) .^{13}$

Definition 2 The equilibrium is a vector of subjectively fair policies $\left\{\hat{q}_{t}^{i}, \hat{b}^{i}\right\}$ and corresponding reference utilities, $\left\{R_{t}^{i}\right\}$, of participation rates, $\left\{p_{t}^{* i}\right\}$, and of actual policies $\left\{q_{t}^{*}, b^{*}\right\}$, such that:

In period 1:

i) The fair policies $\left\{\hat{q}_{1}^{i}, \hat{b}^{i}\right\}$ maximize the modified social welfare functions of each group, (19), taking into account how their period 2 fair policy $\hat{q}_{2}^{i}$ depends on $\hat{b}^{i}$.

ii) Within each group $i$, all members optimally choose whether to riot, given the equilibrium policy $\left\{q_{1}^{*}, b^{*}\right\}$, the group's reference utility $R_{1}^{i}$, and the equilibrium participation of other group members, $p_{1}^{* i}$, and their aggrievements correctly take into account how $b$ affects future equilibrium policies.

iii) The equilibrium policies $\left\{q_{1}^{*}, b^{*}\right\}$ maximize the overall social welfare function, (17), taking as given the groups' reference utilities $\left\{R_{1}^{i}\right\}$, and taking into account how the policy affects equilibrium participation in current and future riots.

In period 2:

i) In each state $b$, the subjectively fair policies $\left\{\hat{q}_{2}^{i}\right\}$ maximize the modified social welfare functions of each group, (18).

ii) Within each group $i$, all members optimally choose whether to riot, given the equilibrium policy $\left\{q_{2}^{*}\right\}$, the group's reference utility $R_{2}^{i}(b)$, and the equilibrium participation of other group members, $p_{2}^{* i}$.

iii) The equilibrium policy $\left\{q_{2}^{*}\right\}$ maximizes overall social welfare in (17), taking as given the groups' reference utilities $\left\{R_{2}^{i}(b)\right\}$, and taking into account how the policy affects equilibrium participation in current riots.

\footnotetext{
${ }^{13}$ We assume throughout the remainder of this section that the government objective function (17) is concave. This requires additional restrictions, besides concavity of $V_{t}^{i}$. In the static model, the proof of Proposition 1 showed that, given concavity of $V^{i}(q)$, the function $P^{i}(q)$ is convex. Here the properties of $P_{t}^{i}$ also depend on the equilibrium function $G(b)$, however, which is defined only implicitly. Hence convexity of $P_{t}^{i}(q, b)$ is a more restrictive assumption than just concavity of $V_{t}^{i}\left(q_{t}, b\right)$.
} 


\subsection{Public debt}

We now illustrate this equilibrium in a dynamic version of the previous model of redistribution. The main result is that the threat of unrest also gives rise to an intertemporal distortion. The government deviates from perfect tax smoothing and issues more debt than economically efficient. The reason is the resignation effect discussed above: issuing debt enables the government to expand redistribution today, thus pleasing the poor, while making the entire society less demanding (and hence less rioting) in the future.

\subsubsection{The economy}

Consider the same economy as in subsection 2.4, except that here there are two periods, $t=1,2$. Individuals who are poor in period 1 remain poor in period 2 , and the same applies to the rich. There is no discounting. The only novelty is that now in period 1 the government can also issue public debt, $b$, which has to be repaid in full next period, and in equilibrium it earns no interest. ${ }^{14}$ Thus, we implicitly assume that default costs are so high that defaulting on the government debt is not an option. With this notation, the indirect utility functions of the two groups are:

$$
\begin{aligned}
V_{t}^{r}\left(\tau_{t}\right) & =1-\tau_{t} \quad t=1,2 \\
V_{1}^{p}\left(\tau_{1}, b\right) & =\tau_{1}+b-F\left(\tau_{1}\right), \quad V_{2}^{p}\left(\tau_{2}, b\right)=\tau_{2}-b-F\left(\tau_{2}\right)
\end{aligned}
$$

where $F\left(\tau_{t}\right)=\tau_{t}^{2} / 2 \alpha$ is the deadweight loss of taxation as in the static model, and where the RHS of (25) also coincide with the subsidies paid to the poor in periods 1 and $2, s_{1}$ and $s_{2}$ respectively. Aggregate economic welfare in period $t$ is defined in the usual way, namely:

$$
W_{t}\left(\tau_{t}, b\right) \equiv \frac{1}{2} V_{t}^{r}\left(\tau_{t}\right)+\frac{1}{2} V_{t}^{p}\left(\tau_{t}, b\right)
$$

It is easy to show that, in the absence of any political constraints, the efficient policy continues to entail no policy intervention and no public debt: $\tau_{t}^{0}=b^{0}=0$.

The timing of events and the equilibrium are as described in the previous subsection. In each period individuals form expectations of fair policies for the current period and derive the corresponding reference utilities $R_{t}^{i}$. The government then sets current policy. Having observed the policy, individuals choose whether to riot. We now characterize the equilibrium, working backwards from period $2 .{ }^{15}$

\footnotetext{
${ }^{14}$ Given the assumption on preferences and the absence of outside assets, the equilibrium real interest rate is zero.

${ }^{15}$ Note the asymmetry: the government can commit to repay its debt obligations, while fiscal policy is chosen sequentially. This assumption is common in the literature on public debt accumulation. It reflects the idea that breaking a formal contractual obligation is more costly and more difficult than modifying a policy
} 


\subsubsection{Period 2}

Fair policies, aggrievements and riots At the start of period 2, individuals observe the initial stock of debt, $b$. The fair policy, $\hat{\tau}_{2}^{i}$, maximizes the following modified social welfare function, subject to $\tau_{2}-\tau_{2}^{2} / 2 \alpha \geq b$ :

$$
W_{2}^{i}\left(\tau_{2}, b\right) \equiv \pi^{i r} \cdot\left(1-\tau_{2}\right)+\pi^{i p} \cdot\left(\tau_{2}-\tau_{2}^{2} / 2 \alpha-b\right), \quad i=r, p
$$

where $\pi^{i k}=\frac{1}{2}(1+\delta)$ if $i=k$, and $\pi^{i k}=\frac{1}{2}(1-\delta)$ if $i \neq k(i, k=r, p)$.

Repeating the steps of subsection 2.4, it is easy to show that the rich want zero subsidies for the poor sector, $\hat{s}_{2}^{r}=0$, and a tax rate which is just sufficient to service the debt: $\hat{\tau}_{2}^{r}=T^{r}(b)$, where the function $T^{r}(b)$ solves the second period budget constraint, $\tau_{2}-\tau_{2}^{2} / 2 \alpha-b=0$, and it is increasing in $b .{ }^{16}$ What about the policy deemed fair by the poor, $\hat{\tau}_{2}^{p}$ ? Suppose that $b$ is sufficiently small, so that the fair policy is an interior optimum of the poor's modified social welfare function (27). Then, repeating the analysis of subsection $2.4, \hat{\tau}_{2}^{p}=2 \delta \alpha /(1+\delta)$ as in the static model. The corresponding fair subsidy is then obtained from the government budget constraint: $\hat{s}_{2}^{p}=\hat{\tau}_{2}^{p}-\left(\hat{\tau}_{2}^{p}\right)^{2} / 2 \alpha-b$. This fair policy is consistent with positive subsidies for $b<\bar{b}$, where

$$
\bar{b} \equiv \hat{\tau}_{2}^{p}-\left(\hat{\tau}_{2}^{p}\right)^{2} / 2 \alpha=2 \delta \alpha /(1+\delta)^{2}
$$

If $b$ exceeds the threshold $\bar{b}$, the fair tax rate $\hat{\tau}_{2}^{p}$ can no longer service the debt and also pay a positive subsidy. Hence, for $b \geq \bar{b}$ the poor are forced to accept $\hat{s}_{2}^{p}=0$, and their subjectively fair tax rate coincides with that of the rich. Note that the threshold $\bar{b}$ is increasing in $\delta$, the parameter capturing self-serving bias.

These fair policies imply corresponding reference utilities for both sectors,

$$
\begin{aligned}
& R_{2}^{r}(b)=1-T^{r}(b) \\
& R_{2}^{p}(b)=\operatorname{Max}\left[0, \hat{\tau}_{2}^{p}-\left(\hat{\tau}_{2}^{p}\right)^{2} / 2 \alpha-b\right]=\operatorname{Max}\left[0,2 \delta \alpha /(1+\delta)^{2}-b\right]
\end{aligned}
$$

These reference utilities depend negatively on initial debt because, for the rich the subjectively fair tax rate, $T^{r}(b)$ increases in $b$, and for the poor the level of subsidies deemed fair decreases in $b$ (until subsidies are zero because $b \geq \bar{b}$ ).

Equilibrium riots continue to be given by (4) (with $\lambda^{i}=1 / 2$ ), except that now, using

already in place. In this context, however, the assumption has additional implications. If debt default was a conceivable policy option, then some groups may conceive it as a fair policy and the resignation effect could be mitigated.

${ }^{16}$ Differentiating the second period budget constraint with respect to $b$, we have: $T_{b}^{r}=\alpha /\left(\alpha-\hat{\tau}_{2}^{r}\right)>0$. 
(24-25) and (29-30), aggrievements $\operatorname{are}^{17}$ :

$$
\begin{aligned}
& A_{2}^{r}\left(\tau_{2}, b\right)=\frac{\omega}{2} \operatorname{Max}\left[0, \tau_{2}-T^{r}(b)\right]^{2} \\
& A_{2}^{p}\left(\tau_{2}, b\right)=\frac{\omega}{2} \operatorname{Max}\left[0,2 \delta \alpha /(1+\delta)^{2}-\tau_{2}+F\left(\tau_{2}\right)\right]^{2}
\end{aligned}
$$

Repeating the same steps as in subsection 2.4, it is easy to show that Lemma 1 continues to hold, so that higher taxes reduce riots by the poor and increase riots by the rich: $P_{2 \tau}^{p}\left(\tau_{2}, b\right) \leq$ $0 \leq P_{2 \tau}^{r}\left(\tau_{2}, b\right)$, with strict inequality if and only if sector $i$ is aggrieved. But here we get an additional result, namely a higher initial debt reduces riots by the rich, for a given tax rate. Riots by the poor instead do not depend on $b$. Specifically, differentiating (31-32) with respect to $b$, and recalling that $P_{2 b}^{i}\left(\tau_{2}, b\right)$ has the same sign as $A_{2 b}^{i}\left(\tau_{2}, b\right)$ (by (8)) and that $T_{b}^{r}=\frac{\alpha}{\alpha-\hat{\tau}_{2}^{r}}>0$ (by footnote 16 ) we have:

Lemma $2 P_{2 b}^{p}\left(\tau_{2}, b\right)=0 \geq P_{2 b}^{r}\left(\tau_{2}, b\right)$, with strict inequality if and only if $r$ is aggrieved (i.e. if and only if $\left.\tau_{2}>T^{r}(b)\right)$.

To see the intuition, suppose that there is social conflict over tax policy (i.e. we are in the region $b<\bar{b}$, so that $\hat{\tau}_{2}^{p}>\hat{\tau}_{2}^{r}$ ). The poor are aggrieved if they do not get the positive subsidy they feel entitled to. Conversely, the rich feel aggrieved if taxes are used to pay for subsidies, and not just to service the debt. As initial debt increases, the two groups become less far apart. In particular, holding $\tau_{2}$ constant, a higher initial debt reduces rioting by the rich (if they are aggrieved), while it has no effect on riots by the poor $\left(P_{2 b}^{r}\left(\tau_{2}, b\right) \leq 0\right.$ and $\left.P_{2 b}^{p}\left(\tau_{2}, b\right)=0\right)$. This happens because, as initial debt increases, both sectors reduce their expectations of what they are entitled to (by (29-30) both $R_{2}^{r}(b)$ and $R_{2}^{p}(b)$ are decreasing in $b$ ). However, for a given tax rate, a higher value of $b$ reduces reference utility and actual utility of the poor by the same amount (as actual subsidies also go down). These two effects exactly cancel out, so the poor aggrievement and participation rate do not depend on $b$ for a given tax rate. By contrast, a higher debt reduces the reference utility of the rich, but it does not affect their actual utility (given the tax rate $\tau_{2}$ ). So the rich are less aggrieved as $b$ rises, because for a given $\tau_{2}$ a larger share of the tax burden is used to repay the debt, rather than to finance subsidies. Hence they riot less.

This result reflects the resignation effect stressed in the previous section. As the circumstances change, individual notions of what is fair adapt. In particular, rational individuals take into account the policymaker's constraints and scale down their entitlements accordingly. As initial debt increases, all groups in society become resigned to a lower level of welfare: the rich accept to pay higher taxes, and the poor demand lower subsidies.

\footnotetext{
${ }^{17}$ If taxes are so low that subsidies are 0 , then $b$ cannot increase without also raising $\tau_{2}$. Neverthless, $(32)$ still follows from (25) and (30), because by the government budget constraint $b=\tau_{2}-F\left(\tau_{2}\right)$.
} 
Equilibrium policy The government maximizes period 2 social welfare inclusive of the social cost of riots:

$$
W_{2}\left(\tau_{2}, b\right)-\frac{\varsigma}{2}\left[P_{2}^{p}\left(\tau_{2}, b\right)+P_{2}^{r}\left(\tau_{2}, b\right)\right]
$$

taking $b$ as given and subject to the non-negativity constraint $\tau_{2}-F\left(\tau_{2}\right)-b \geq 0$, and where $W_{2}\left(\tau_{2}, b\right)=\frac{1}{2}\left[1-\tau_{2}^{2} / 2 \alpha-b\right]$ by (24-26). The optimality condition is:

$$
\tau_{2} \geq-\alpha \varsigma\left[P_{2 \tau}^{p}\left(\tau_{2}, b\right)+P_{2 \tau}^{r}\left(\tau_{2}, b\right)\right]
$$

with strict inequality implying $s_{2}^{*}=0$. Equation (33) and the government budget constraint, $s_{2}=\tau_{2}-b-F\left(\tau_{2}\right)$, define the equilibrium tax rate and subsidy as implicit functions of initial debt: $\tau_{2}^{*}=T(b)$ and $s_{2}^{*}=S(b)$. The Appendix proves:

Proposition 3 In the second period, the equilibrium tax rate is strictly positive and increasing in $b: T(b)>0$ and $T_{b}>0$. The equilibrium subsidy $S(b)$ is positive or zero, depending on the level of $b$, and it is (weakly) decreasing in $b$. There is a threshold level of debt, $0<\tilde{b}<\bar{b}$, such that if $b<\tilde{b}$ then $S(b)>0$ and $S_{b}<0$, while for $b \geq \tilde{b}$ we have $S(b)=0$.

The result of a positive equilibrium tax rate, even for $b=0$, is the same as in Proposition 2 above. As explained in the previous section, this happens because, at the efficient policy, the rich are not aggrieved and hence do not riot (except for those for which $\left.\varepsilon^{i j} \leq-\mu\right)$ ). As initial debt increases, the equilibrium policy converges towards the economically efficient one, and once $b \geq \tilde{b}$ economic efficiency is achieved. This result reflects the resignation effect discussed earlier. Consider the effect of a larger initial debt in the range $b<\tilde{b}$. The rich realize that a larger debt service implies that taxes have to be raised, and reduce their aggrievement for any given tax rate. This allows the government to raise the tax rate without aggrieving the rich. As this happens, the poor too become less aggrieved, which allows the government to marginally cut subsidies in order to gain efficiency. Once $b$ reaches the threshold $\tilde{b}$, subsidies reach zero and the equilibrium policy coincides with the efficient one, even though the poor remain aggrieved as long as $b<\bar{b}$.

Figure 1 here

\section{Labelling: Figure 1. Taxes, subsidies, and riots in period 2}

The upper graph of Figure 1 illustrates the equilibrium as a function of $b$. At the point $b=0$, subsidies coincide with tax revenues: $s_{2}^{*}=\tau_{2}^{*}-F\left(\tau_{2}^{*}\right)$. As $b$ increases, equilibrium

subsidies (the bold decreasing curve, $s_{2}^{*}$ ) decrease up to $\tilde{b}$, and are zero for $b>\tilde{b}$. The subsidies deemed fair by the poor (the dashed decreasing curve, $\hat{s}_{2}^{p}$ ) are higher and vanish above $\bar{b}$. The level of taxation deemed fair by the rich, $\hat{\tau}_{2}^{r}-F\left(\hat{\tau}_{2}^{r}\right)$, coincides with the $45^{\circ}$ 
curve. The equilibrium level of taxation (the bold increasing curve, $\tau_{2}^{*}-F\left(\tau_{2}^{*}\right)$ ) remains higher than deemed fair by the rich until $\tilde{b}$.

The model also yields some implications about how equilibrium riots vary with $b$. If $b \geq \bar{b}$, then in equilibrium neither the rich nor the poor are aggrieved: the rich are not aggrieved because taxation is used to service the debt only, and the poor do not expect to receive any subsidy. Hence if debt is above $\bar{b}$ there are no riots in equilibrium (except for those for which $\left.\varepsilon^{i j} \leq-\mu\right)$. Consider the range $b<\bar{b}$. Taking the total derivative of $P_{2}^{p}\left(\tau_{2}, b\right)+P_{2}^{r}\left(\tau_{2}, b\right)$ with respect to $b$ at the equilibrium policy $\tau_{2}^{*}=T(b)$, we get:

$$
P_{2 b}^{p}+P_{2 b}^{r}+T_{b}\left(P_{2 \tau}^{p}+P_{2 \tau}^{r}\right)
$$

By Lemma $2, P_{2 b}^{p}=0$ and $P_{2 b}^{r} \leq 0$. By Proposition $3, T_{b}>0$. The term inside the parentheses has the opposite sign of the LHS of (33), and hence it is negative in equilibrium. Hence, the whole expression is negative. Thus we have:

Proposition 4 The total equilibrium incidence of riots in period 2 decreases with $b$, and it reaches a minimum at $b=\bar{b}$.

These results are illustrated in the lower graph of Figure 1. The rich stop being aggrieved as soon as taxes equal debt (i.e. $b \geq \tilde{b}$ ). The poor do so when the debt is so high that their entitlements are zero $(b \geq \bar{b})$. In the range $\tilde{b} \leq b<\bar{b}$ the poor receive no subsidy, however their aggrievement decreases because their entitled utility, $R_{2}^{p}$, decreases as taxation to repay debt increases (or equivalently, because equilibrium taxes increase in order to service the debt - cf. (32) and footnote 17). Finally, and as in Proposition 2, it can be shown that in equilibrium the poor protest more than the rich.

\subsubsection{Period 1}

Fair policies, aggrievements and riots To form expectations of fair policies $\hat{\tau}_{1}^{i}, \hat{b}^{i}$, individuals maximize the modified social welfare function

$$
W_{1}^{i}\left(\tau_{1}, b\right)+W_{2}^{i}\left(T^{i}(b), b\right) \quad i=r, p
$$

with respect to $\tau_{1}$, and $b$, where the function $T^{i}(b)$ defines the period 2 policies deemed fair by $i$ in period 2, as a function of $b$, and derived in the previous subsection. The first term in (34) is $W_{1}^{i}\left(\tau_{1}, b\right) \equiv \pi^{i r} \cdot\left(1-\tau_{1}\right)+\pi^{i p} \cdot\left[\tau_{1}+b-\tau_{1}^{2} / 2 \alpha\right]$, while $W_{2}^{i}($.$) is given by (27), with$ $\tau_{2}=T^{r}(b)$ for $i=r$, and $\tau_{2}=\hat{\tau}_{2}^{p}$ for $i=p$. The weights $\pi^{i r}$ and $\pi^{i p}$ reflect self-serving bias, as defined above.

Repeating the previous steps, it is easy to show that the fair tax rates are as in the static model, namely they are zero for the rich and positive for the poor: $\hat{\tau}_{1}^{r}=0$ and $\hat{\tau}_{1}^{p}=$ 
$2 \delta \alpha /(1+\delta)>0$. What about fair debt? Issuing debt raises current subsidies, but entails future expected costs. The rich do not fully internalize the current benefits of more borrowing, because they realize that the main beneficiaries are the poor. They also realize that higher debt will induce them to accept higher taxes tomorrow, since $\hat{\tau}_{2}^{r}=T^{r}(b)$ is an increasing function of $b$. Hence their fair debt is zero. The poor internalize the benefit of higher current subsidies more than a benevolent social planner, given that $\delta>0$. They also realize that higher debt will induce them to accept lower subsidies tomorrow, however, and that this effect will be one for one (since $\hat{\tau}_{2}^{p}$ does not depend on $b$ ). These two effects exactly cancel out, and the fair level of debt for the poor is indeterminate (their lifetime reference utility does not depend on $b$ ). More precisely (the formal proof is in Appendix):

Lemma 3 i) In period 1 the fair tax rates are as in the static model: $\hat{\tau}_{1}^{r}=0$ and $\hat{\tau}_{1}^{p}=$ $2 \delta \alpha /(1+\delta)>0$. ii) The fair debt is zero for the rich $\left(\hat{b}^{r}=0\right)$ and indeterminate for the poor.

These fair policies imply corresponding reference utilities for both sectors, namely:

$$
\begin{aligned}
& R_{1}^{r}=1-\hat{\tau}_{1}^{r}+1-T^{r}\left(\hat{b}^{r}\right)=2 \\
& R_{1}^{p}=\hat{\tau}_{1}^{p}-F\left(\hat{\tau}_{1}^{p}\right)+\hat{\tau}_{2}^{p}-F\left(\hat{\tau}_{2}^{p}\right)=4 \delta \alpha /(1+\delta)^{2}
\end{aligned}
$$

Repeating the steps above, we can then write period 1 aggrievements as: ${ }^{18}$

$$
\begin{aligned}
& A_{1}^{r}\left(\tau_{1}, b\right)=\frac{\omega}{2} \operatorname{Max}\left[0, \tau_{1}+T(b)\right]^{2} \\
& A_{1}^{p}\left(\tau_{1}, b\right)=\frac{\omega}{2} \operatorname{Max}\left[0,4 \delta \alpha /(1+\delta)^{2}-\tau_{1}-T(b)+F\left(\tau_{1}\right)+F(T(b))\right]^{2}
\end{aligned}
$$

Thus, in period 1 the rich are aggrieved if throughout their lifetime they pay positive taxes (or expect to do so along the equilibrium path). And the poor are aggrieved if they don't receive the subsidies they feel entitled to (currently or in the future along the equilibrium path). Note that these aggrievements fully internalize the future equilibrium consequences of issuing government debt, through the equilibrium function $\tau_{2}=T(b)$.

Differentiating these expressions, and recalling that $P_{q}^{i}$ has the same sign as $A_{q}^{i}$ (by (8)) and that $T_{b}(b)>0$, we immediately obtain:

Lemma $4 P_{1 \tau}^{r}\left(\tau_{1}, b\right) \geq 0 \geq P_{1 \tau}^{p}\left(\tau_{1}, b\right)$ and $P_{1 b}^{r}\left(\tau_{1}, b\right) \geq 0 \geq P_{1 b}^{p}\left(\tau_{1}, b\right)$ with strict inequalities if $i$ is aggrieved.

Thus, as above, raising taxes pleases the poor and hurts the rich, and riots respond accordingly (as long as the sector is aggrieved). Issuing debt aggrieves the rich, since they realize

\footnotetext{
${ }^{18}$ In the range $b \geq \tilde{b}$ equilibrium subsidies are 0 in period 2 , but $b=T(b)-F(T(b))$ by the government budget constraint, so the expression for $A_{1}^{p}\left(\tau_{1}, b\right)$ is given by (38) for all values of $b$.
} 
that future equilibrium taxes will be raised. For a given tax rate $\tau_{1}$, the aggrievement of the poor is dampened by more debt, for the same reason, as they realize that future equilibrium taxes will be raised (or, in the range $b \geq \tilde{b}$, that current subsidies increase without incurring any future costs since $S(b)=0$ for $b \geq \tilde{b}$ ). To put it another way: the poor are the only current beneficiaries of higher debt, since for a given tax rate $\tau_{1}$ issuing debt raises current subsidies. The future cost of servicing the debt is shared by rich and poor, however, since in equilibrium future taxes also increase with $b$ (future equilibrium subsidies go down as $b$ increases, but less than one for one). Hence, for a given tax rate $\tau_{1}$, issuing debt aggrieves the rich and satisfies the poor.

Equilibrium policy The government sets $\tau_{1}$ and $b$ to maximize the following social welfare function, which includes current and future social costs of riots:

$$
W_{1}\left(\tau_{1}, b\right)+W_{2}\left(\tau_{2}^{*}, b\right)-\frac{\varsigma}{2} \sum_{i=r, p} P_{1}^{i}\left(\tau_{1}, b\right)-\frac{\varsigma}{2} \sum_{i=r, p} P_{2}^{i}\left(\tau_{2}^{*}, b\right)
$$

where $W_{t}\left(\tau_{t}, b\right)$ is defined in (24-26), and $\tau_{2}^{*}=T(b)$ is the future equilibrium policy.

Here too the economically efficient policy, $\tau_{1}^{0}=b^{0}=0$, cannot be an equilibrium. To mitigate riots, in equilibrium the government provides subsidies to the poor, financing them with a mix of debt and current taxes. Here is the general intuition of why the government finds it optimal to borrow. Issuing debt provides two political benefits. First, in a neighborhood of $b=0$, it dampens political conflict and reduces total riots in period 1 . This may seem surprising, because issuing debt aggrieves the rich who anticipate higher future taxes. But as stated in Lemma 4, the poor become less aggrieved, because their lifetime income increases with $b$. Since in equilibrium the poor protest more than the rich and their participation is more sensitive to policy (recall Proposition 2), issuing debt in a neighborhood of $b=0$ reduces total riots in period 1 . This political gain in period 1 comes with no political costs in period 2 . On the contrary, and this is the second political advantage, issuing debt also reduces future riots by the rich. The reason is the resignation effect discussed in Lemma 2. Hence, a government caring about social conflict has an incentive to partly finance current subsides through a mix of debt and taxes, up to the point where $\tau_{1}^{*}<\tau_{2}^{*}$.

We prove this result in steps. We start with the following

Lemma 5 If $b \leq 0$, then $\tau_{1}^{*}>\tau_{2}^{*}$.

Here $\tau_{t}^{*}$ denotes equilibrium taxes in period $t$, given $b$. Although the formal proof is long, and we leave it to the Appendix, the intuition is quite simple. In both periods, the government leaves the poor more disappointed than the rich in equilibrium. The reason is the same as in Proposition 2: transfers impose deadweight losses. Thus, pleasing the poor is at the margin 
more costly than pleasing the rich. At $b=0$, social conflict is more intense in period 1 than in period 2, since aggrievements are forward looking and individuals anticipate their second period disappointments. A more intense social conflict calls for higher taxes in period 1 than in period 2. Hence a government that cannot issue debt finds it optimal to set $\tau_{1}>\tau_{2}$. This reasoning is reinforced if $b<0$.

Next, we show that, in the range $b \leq 0$, total equilibrium riots in period 1 are decreasing in $b$ (where again $\tau_{1}^{*}$ denotes the equilibrium tax in period 1 , given $b$ ):

Lemma 6 If $b \leq 0$, then $P_{1 b}^{r}\left(\tau_{1}^{*}, b\right)+P_{1 b}^{p}\left(\tau_{1}^{*}, b\right)<0$.

Proof. By (8),

$$
\begin{aligned}
P_{1 b}^{i} & =\frac{1}{2(\sigma-\mu)}\left(P_{1}^{i}\right)^{2} A_{1 b}^{i}=\frac{1}{2(\sigma-\mu)}\left(P_{1}^{i}\right)^{2} A_{1 \tau}^{i}\left(A_{1 b}^{i} / A_{1 \tau}^{i}\right) \\
& =P_{1 \tau}^{i} A_{1 b}^{i} / A_{1 \tau}^{i}
\end{aligned}
$$

Since by (37), $A_{1 b}^{r} / A_{1 \tau}^{r}=T_{b}$ and by (38) $A_{1 b}^{p} / A_{1 \tau}^{p}=\frac{\alpha-T(b)}{\alpha} T_{b} / \frac{\alpha-\tau_{1}}{\alpha}=T_{b} \frac{\alpha-\tau_{2}}{\alpha-\tau_{1}}$, we have:

$$
\begin{aligned}
P_{1 b}^{r}\left(\tau_{1}, b\right) & =P_{1 \tau}^{r}\left(\tau_{1}, b\right) T_{b}(b) \\
P_{1 b}^{p}\left(\tau_{1}, b\right) & =P_{1 \tau}^{p}\left(\tau_{1}, b\right) T_{b}(b) \frac{\alpha-\tau_{2}}{\alpha-\tau_{1}}
\end{aligned}
$$

Since $\frac{\alpha-\tau_{2}}{\alpha-\tau_{1}}=1+\frac{\tau_{1}-\tau_{2}}{\alpha-\tau_{1}}$, we then have:

$$
P_{1 b}^{p}+P_{1 b}^{r}=T_{b}\left[P_{1 \tau}^{r}+P_{1 \tau}^{p}\right]+T_{b} P_{1 \tau}^{p} \frac{\tau_{1}-\tau_{2}}{\alpha-\tau_{1}}
$$

The optimality condition with respect to $\tau_{1}$ can be written like (16) in the static model, and thus implies $P_{1 \tau}^{r}+P_{1 \tau}^{p}<0$ when evaluated at $\tau_{1}^{*}$. A fortiori, $P_{1 \tau}^{p}<0$ (see also Lemma 4). By Lemma $5, \tau_{1}^{*}-\tau_{2}^{*}>0$. Finally, by Proposition $3, T_{b}>0$. Hence all terms on the RHS of (42) are negative at the equilibrium taxes, which proves the Lemma.

This result is important, because it says that, in the range $b \leq 0$, raising $b$ brings about a political gain in period 1 , since it reduces total riots in the current period. The reason is that, although a higher debt hurts the rich, it pleases the poor (see Lemma 4). The marginal effect on the poor is bigger than on the rich, because the poor are more aggrieved. Hence total riots in period 1 go down as debt increases (in the range $b \leq 0$ ). In other words, for $b \leq 0$ raising debt is an additional useful instrument to dampen social conflict in period 1.

But we have already seen that higher debt always reduces social conflict in period 2 , by the resignation effect (see Lemma 2). Hence in equilibrium the government must find it optimal to borrow a positive amount, until the political benefits of government debt are offset by 
excessively high tax distortions in period 2. This is what Proposition 5 below says. It also says that the equilibrium tax is lower in period 1 than in period 2.

Proposition 5 In equilibrium, $b^{*}>0$, and $0<\tau_{1}^{*}<\tau_{2}^{*}$.

Proof. Consider first the optimality condition with respect to $\tau_{1}$. At an interior optimum it can be written as:

$$
\tau_{1}=-\alpha \varsigma\left[P_{1 \tau}^{p}\left(\tau_{1}, b\right)+P_{1 \tau}^{r}\left(\tau_{1}, b\right)\right]
$$

Repeating the steps in Proposition 2, this equation implies that $\tau_{1}^{*}>0$.

Next, consider the optimality condition with respect to $b$. For $b<\tilde{b}$ (i.e. if $s_{2}^{*}>0$ ) and for given tax rates, issuing debt only changes the time profile of subsidies. Since preferences are linear in private consumption, we have $W_{1 b}\left(\tau_{1}, b\right)=\frac{1}{2}=-W_{2 b}\left(\tau_{2}^{*}, b\right)$. Thus, in the range $b<\tilde{b}$ the optimal level of debt minimizes total unrest in period 1 and period 2 , and at an interior optimum the optimality condition for a maximum of (39) with respect to $b$ simplifies to:

$$
-\left[P_{1 b}^{r}+P_{1 b}^{p}+P_{2 b}^{r}+P_{2 b}^{p}\right]=0
$$

By Lemma $6, P_{1 b}^{r}+P_{1 b}^{p}<0$ in the region $b \leq 0$. By Lemma $2, P_{2 b}^{r}<0=P_{2 b}^{p}$ (recall that in equilibrium group $r$ is aggrieved if $b<\tilde{b})$. Hence, in the range $b \leq 0$ the LHS of (44) is strictly positive, implying that $b^{*}>0$.

To prove that $\tau_{1}^{*}<\tau_{2}^{*}$ in the range $b<\tilde{b}$, use (42) and $P_{2 b}^{p}=0$ to rewrite (44) as:

$$
-\left\{T_{b}\left[P_{1 \tau}^{r}+P_{1 \tau}^{p}\right]+P_{1 \tau}^{p} T_{b} \frac{\tau_{1}-\tau_{2}}{\alpha-\tau_{1}}+P_{2 b}^{r}\right\}=0
$$

Repeating the previous arguments, all the terms in LHS of (45) are negative, except for the second one. Since $P_{1 \tau}^{p}<0<T_{b}$, in equilibrium we must have $\tau_{1}^{*}<\tau_{2}^{*}$. The Appendix completes the proof, showing that the same conclusion holds in the range $b \geq \tilde{b}$, by a similar argument. ${ }^{19}$

Summarizing, issuing government debt has two political benefits. First, it provides an additional instrument to reduce social conflict in period 1, besides distorting taxes. As explained in Lemma 4, issuing debt dampens aggrievement by the poor. This makes the rich more angry in period 1, but the government responds by reducing period 1 tax rates. Taxes have to go up in the future of course, and the rich anticipate this. But, and this is the second political benefit of issuing debt, the resignation effect reduces their future riots. Hence this policy combination, of higher $b$ and lower $\tau_{1}$, enables the government to exploit the resignation effect and to reduce overall social conflict in both periods. The government finds it optimal

\footnotetext{
${ }^{19}$ We cannot tell whether in equilibrium $b^{*} \lessgtr \tilde{b}$.
} 
to continue with this policy until tax distortions are higher in the second period than in the first one (i.e. $\tau_{1}^{*}<\tau_{2}^{*}$ ).

Although the details of the equilibrium depend on some of the special features of the model, and in particular on linear preferences for consumption, the nature of the distortions is general. Excessive redistribution $\left(\tau_{t}^{*}>0\right)$ results from the fact that, at the efficient policy, the rich are not aggrieved and thus they do not exert any political influence. The intertemporal distortion is a by-product of the resignation effect discussed above. To see this, suppose that reference utilities are not determined sequentially, but instead are formed once and for all at the beginning of period 1 , so that period 2 reference utilities do not depend on $b$ and the resignation effect is not operative. In this alternative formulation, issuing government debt raises future social conflict, rather than reducing it. The reason is that actual period 2 welfare is pushed further below the predetermined reference utilities for both groups. Hence, the period 1 political benefit associated with borrowing would be offset by a harsher conflict and more riots in period 2 .

Finally, a previous version considered the case of myopic aggrievements, in which individuals only care about the gap between reference and actual utility in the current period, disregarding the future expected gap. Not surprisingly, the equilibrium policy now becomes even more shortsighted, and the equilibrium level of debt increases further, up to the point

in which in equilibrium $s_{2}^{*}=0$ and equilibrium debt lies in the range $[\tilde{b}, \bar{b})$. All the other properties of the equilibrium continue to hold.

\section{Some evidence}

We now explore some evidence in light of the implications of the theory.

\subsection{Who riots?}

Who typically participates in riots and other protests? Survey data can be used to answer this question. The European Social Survey (ESS) and the World Value Survey (WVS) ask whether the respondent has attended public demonstrations recently (the WVS) or over the last year (the ESS). In Table 1 we use this as the qualitative dependent variable, and estimate by probit including country and wave fixed effects (see the Online Data Appendix for a precise definition of the variables). In the ESS we have 34 countries and 5 waves during the period 2002-2012 (with the 2006 wave missing). In the WVS we have 36 countries and one wave during the period 2005-2009.

Demonstrators are more likely to have extreme political preferences, to be attached to and involved with specific political parties, and to know for which party they will vote in the next 
election. This is the opposite of the swing voter in theories of probabilistic voting (cf. Persson and Tabellini 2000). They are also more likely to have voted in the last election, to belong to a minority that feels discriminated, to have low income, to be dissatisfied with the government or with specific public policies and to be generally dissatisfied. Several of these features are consistent with the predictions of the theory. Moreover, demonstrators tend to be educated, males, to be in the labor force or students, and to be less than 50 years of age.

\section{Table 1 here}

\subsection{Fiscal retrenchments}

Next, consider the political consequences of fiscal retrenchments. This evidence is puzzling, because fiscal retrenchments are widely regarded as politically very difficult, and yet there is little evidence that voters punish fiscally responsible governments at the elections. Alesina et al. (2012) consider a sample of 19 OECD countries from 1975 to 2008, and show that governments that achieve large reductions in the budget deficit are not punished at the subsequent elections. As suggested by Ponticelli and Voth (2011), a plausible conjecture is that political unrest, rather than majority voting or lobbying behind closed doors, is the form of political participation that discourages fiscal retrenchments.

To explore this conjecture, we define political unrest as the sum of riots, general strikes and anti-government demonstrations, that is as lawful or unlawful collective action aimed against the national political authority and not entailing any military violence (the source is Banks 2012 - see also the Data Appendix). This definition excludes episodes of individual violence, such as terrorism, political assassination and civil wars, as well as protests not aimed against national political authority (e.g. firms, or local governments).

Table 2 uses the same data on fiscal retrenchments and the same sample as Alesina et al. (2012), except that here the dependent variable is political unrest. The specification in column 1 includes the same macroeconomic and policy variables appearing in the core regressions of Alesina et al. (except for features of the government and of the electoral system that here are left out). Column 2 adds year fixed effects. The main variables of interest is the change in cyclically adjusted primary deficit (in \% of GDP). The other regressors are inflation, GDP growth and the growth in unemployment, in the country and also expressed as deviations from the average in the G7 countries (to isolate domestic events from external shocks that also affect the rest of the world). Since political unrest is a count variable, we estimate by Poisson Quasi-Maximum Likelihood methods conditioning on country fixed effects. ${ }^{20}$

\footnotetext{
${ }^{20}$ Most results described below are robust to linear estimation with country fixed effects and standard errors clustered by countries (see Table A2 in the Online Appendix).
} 
The estimated coefficient on the change in primary deficit is always statistically significant and with a negative sign, meaning that a deficit reduction increases political unrest. The estimated coefficient of about -0.2 or -0.3 means that a fiscal adjustment of $1 \%$ of GDP is associated with an increase in political unrest of about $20 \%$ or $30 \%$, a very large effect. The data also reveals that unrest tends to increase during adverse economic conditions (lower GDP growth or higher unemployment growth) and with higher inflation, but these estimates are much less robust and vary across specifications. Overall, these correlations are suggestive that fiscal retrenchments are indeed associated with political unrest.

Next, we ask whether political unrest is mitigated by a higher initial public debt, as predicted by the resignation effect discussed in our theory. Thus, columns 3 and 4 add an additional regressor: the stock of debt in percent of GDP at the beginning of the period, called lagged debt. As expected, the estimated coefficient on lagged debt is always statistically significant and with a negative sign. Its estimated coefficient of about 0.01 implies that an increase of the debt to GDP ratio of 10 percentage points is associated with an average reduction in the incidence of political unrest of about $10 \%$ - a non-negligible amount. The estimated coefficient on the cyclically adjusted primary deficit increases in absolute value and remains highly significant, again as expected.

To explore possible non-linear effects, columns 5-8 reproduce exactly the same specification of columns 1 and 2, but for two different subsamples: for lagged debt above or below the critical threshold of $90 \%$ of GDP. The estimated coefficient on cyclically adjusted budget deficits is statistically significant only if debt is below this threshold. Thus, in accordance with the resignation effect discussed in the theory, fiscal retrenchments are not associated with political unrest if they take place in a high public debt environment. If the threshold that splits the sample is raised to any number between $91 \%$ and $100 \%$ of GDP, all results remain largely unaffected. If the threshold is lowered to anywhere between $80 \%$ and $89 \%$, it remains true that in a low debt environment fiscal retrenchments are correlated with political unrest, but for some specifications fiscal retrenchments are associated with unrest even above the threshold (see Table A3 in the Online Appendix). In other words, debt has to be sufficiently high for the resignation effect to be operative in affecting the reaction to fiscal retrenchments.

Finally, in the Online Appendix we study the relationship between unrest and sovereign debt crises. The logic of the resignation effect suggests that political unrest should precede the crisis rather than follow it. The reasons is that a debt crisis makes it clear to everyone that the government has no options left. This is indeed what we find in the data: political unrest goes up in the year of the debt crisis and two years before, while it tends to go down two years after the crisis.

\section{Table 2 here}




\section{Concluding Remarks}

The ideas and the results developed in this paper can be extended in several fruitful directions.

One of the outstanding puzzles in political economics is why atomistic individuals bother to take costly political actions. The ideas developed in this paper can provide a stepping stone for a more general theory of political participation, that applies to voting and other political activities besides riots. Voters can be more easily mobilized against a candidate or a policy platform perceived as unfair, or to punish an incumbent so as to correct grievances. In particular, the idea that individuals form expectations of what they are entitled to, and that such expectations shape political behavior, could explain protest votes and higher turnout by angry or disappointed voters (cf. Scholzman and Verba 1979). If so, some of the results on the sources of political influence discussed above have wider applicability than just to political protests.

A central insight of the paper is that individuals react emotionally to unfair treatment, but notions of what is fair are internally consistent and adapt to changing circumstances. We have made this idea operational by incorporating the expectation of a fair policy in the definition of equilibrium. As external circumstances deteriorate, individuals become resigned to a lower level of welfare. But the idea that expectations of what is fair are endogenous could have very different implications in other settings. For instance, habit formation could raise voters' expectations of what is a fair level of welfare. Alternatively, status quo policies could provide a reference point that discourages policy reversals, just like ex-post renegotiation is more difficult if the ex-ante contract acts as a reference point (cf. Herweg and Schmidt 2014). If so, policy procrastination or past policy decisions could make voters more entrenched, rather than more resigned. Exploring the circumstances under which entrenchment rather than resignation is more likely is an important item for future research.

This paper studies how the threat of collective action influences public policy, as groups seek to defend their "economic rights". But the same ingredients can be adapted to study the endogenous evolution of political institutions, such as in a transition from autocracy to democracy, when citizens fight to defend their "political rights". This would add other sources of strategic interaction. In the model above, the strategic interaction concerns within-group behavior. The reason is that groups protest against government policy, rather than against other groups. If opposing groups fight each other, as for instance in Acemoglu and Robinson (2006b) or Battaglini and Bénabou (2003), the set of interactions would become richer and additional insights could be obtained.

The model assumes that riots are entirely spontaneous and exclusively motivated by emotions. In reality, political unrest is often initiated by group leaders (such as trade unions) who view riots as instruments to influence future policies or induce policy reversals. Such leaders still need to draw people in the streets, and hence they face constraints similar to 
those discussed in this paper. Incorporating strategic leaders, who deliberately exploit the emotional reaction of group members in order to obtain policy favor for themselves or for the group, could yield additional interesting implications.

The idea that individuals take costly actions to display their aggrievement can also be relevant outside of politics. In particular, voice activities such as customer complaints, or other sanctions, can explain the functioning of organizations in different cultural environments (cf. Akerlof 2012).

Finally, the central role given to notions of fairness and aggrievement opens the door to the possibility of manipulating voters' expectations of what is fair through the media or through social networks. Persuasion plays a central role in politics, but has been largely neglected in political economics, mainly because persuasion is so hard to pin down precisely, but also because much of the literature has focused on the voters' material interests rather than on what they consider fair. Perhaps the framework of this paper can be extended to shed light on these important but difficult issues in the analysis of political behavior.

\section{Appendix ${ }^{21}$}

Proof. Proposition 1 By (9) the second order condition is

$$
W_{q q}\left(q^{*}\right)-\sum_{i} \varsigma^{i} \lambda^{i} P_{q q}^{i}\left(q^{*}\right)<0
$$

By the concavity of all $V^{i}\left(q^{*}\right)$, the first term in (46) is negative. As for the second one, by (4) and (8), $P_{q q}^{i}=\frac{2\left(\lambda^{i}\right)^{2}\left(\sigma^{i}-\mu\right)}{\left(2 \sigma^{i}-a^{i} \lambda^{i}\right)^{3}}\left(A_{q}^{i}\right)^{2}+\frac{\lambda^{i}\left(\sigma^{i}-\mu\right)}{\left(2 \sigma^{i}-a^{i} \lambda^{i}\right)^{2}} A_{q q}^{i} \geq 0$, where the inequality derives from the fact that $A_{q q}^{i}=\omega^{i}\left(V_{q}^{i}\right)^{2}-\omega^{i}\left(R^{i}-V^{i}(q)\right) V_{q q}^{i} \geq 0$ and all other terms in $P_{q q}^{i}$ are positive (strict inequality implies that group $i$ is aggrieved). Then $P_{q q}^{i}(q)$ 's are positive for all $q$ and all $i$, thus (46) is satisfied.

Proof. Proposition 2 The proof of the statement that $\hat{\tau}^{p}>\tau^{*}>0$ is in the text. To prove the statement that $p^{* p}>p^{* r}$, note that the optimality condition (16) implies $\left|P_{\tau}^{p}\right|>P_{\tau}^{r}$, which in turn by (8) can be written as:

$$
\left[P^{p}(\tau)\right]^{2}\left(R^{p}-V^{p}(\tau)\right) V_{\tau}^{p}>-\left[P^{r}(\tau)\right]^{2}\left(R^{r}-V^{r}(\tau)\right) V_{\tau}^{r}
$$

By (11), $V_{\tau}^{p}(\tau)=(\alpha-\tau) / \alpha<1=-V_{\tau}^{r}(\tau)$ so that (47) together with (8), (7) and (6) implies $A^{p}\left(\tau^{*}\right)>A^{r}\left(\tau^{*}\right)$. Hence by $(7) P^{p}\left(\tau^{*}\right)>P^{r}\left(\tau^{*}\right)$.

\footnotetext{
${ }^{21}$ The proofs of Proposition 4, and Lemmas 2 and 4 coincide with the discussion in the text. Thus we omit them.
} 
Proof. Proposition 3 (i) Proposition 2 proves that $\tau_{2}^{*}>0$ and $s_{2}^{*}>0$ for $b=0$. Hence the equilibrium tax rate $\tau_{2}^{*}=T(b)$ is always positive if $T(b)$ is increasing, which we prove below. (ii) Suppose first that the optimality condition (33) holds as equality, because the nonnegativity constraint on $s_{2}$ does not bind. We then show that $\tau_{2}^{*}=T(b)$ is strictly increasing in $b$, and that equilibrium subsidies $s_{2}^{*}=S(b)$ are strictly decreasing in $b$. Applying the implicit function to (33) yields,

$$
T_{b}=\frac{\partial \tau_{2}^{*}}{\partial b}=\frac{\varsigma\left[P_{2 \tau b}^{p}\left(\tau_{2}^{*}, b\right)+P_{2 \tau b}^{r}\left(\tau_{2}^{*}, b\right)\right]}{2 S O C_{\tau_{2}}}>0
$$

where

$$
S O C_{\tau_{2}}=-\frac{1}{2 \alpha}-\frac{\varsigma}{2}\left(P_{2 \tau \tau}^{r}+P_{2 \tau \tau}^{p}\right)<0
$$

is negative by the second order conditions - see the Proof of Proposition 1. By Lemma 2, $P_{2 \tau b}^{p}\left(\tau_{2}^{*}, b\right)=0$. The numerator's sign is given by the sign of:

$$
P_{2 \tau b}^{r}=\frac{1}{2(\sigma-\mu)^{2}}\left(P_{2}^{r}\right)^{3} A_{2 \tau}^{r} A_{2 b}^{r}+\frac{1}{2(\sigma-\mu)}\left(P_{2}^{r}\right)^{2} A_{2 \tau b}^{r}
$$

We now prove that the RHS of this expression is negative. Differentiating (31) and recalling that $T_{b}^{r}=\frac{\alpha}{\alpha-\hat{\tau}_{2}^{r}}$ yields

$$
\begin{gathered}
A_{2 \tau}^{r}=\omega\left[\tau_{2}-T^{r}(b)\right]>0 \quad A_{2 b}^{r}=-\omega\left[\tau_{2}-T^{r}(b)\right] \frac{\alpha}{\alpha-\hat{\tau}_{2}^{r}}<0 \\
A_{2 \tau b}^{r}=-\omega \frac{\alpha}{\alpha-\hat{\tau}_{2}^{r}}<0
\end{gathered}
$$

Hence $P_{2 \tau b}^{r}<0$ which in turn implies $T_{b}>0$.

The equilibrium subsidy is $s_{2}^{*}=T(b)-\frac{T(b)^{2}}{2 \alpha}-b \equiv S(b)$. Differentiating with respect to $b$ yields:

$$
S_{b}=T_{b} \frac{\alpha-\tau_{2}^{*}}{\alpha}-1
$$

Inserting (49) in (48), and inserting the latter in (52), we have that $S_{b}<0$ if:

$$
\frac{1}{\alpha}+\varsigma\left[\sum_{i=p, r} P_{2 \tau \tau}^{i}+\frac{\alpha-\tau_{2}^{*}}{\alpha} P_{2 \tau b}^{r}\right]>0
$$

The first term is positive. Consider $\sum_{i=p, r} P_{2 \tau \tau}^{i}+\frac{\alpha-\tau_{2}^{*}}{\alpha} P_{2 \tau b}^{r}$. It can be written as:

$$
\begin{gathered}
\frac{1}{2(\sigma-\mu)^{2}}\left[P_{2}^{p}\right]^{3}\left[A_{2 \tau}^{p}\right]^{2}+\frac{1}{2(\sigma-\mu)^{2}}\left[P_{2}^{r}\right]^{3} A_{2 \tau}^{r}\left(A_{2 \tau}^{r}+\frac{\alpha-\tau_{2}^{*}}{\alpha} A_{2 b}^{r}\right) \\
+\frac{1}{2(\sigma-\mu)}\left[P_{2}^{r}\right]^{2}\left(A_{2 \tau \tau}^{p}+A_{2 \tau \tau}^{r}+\frac{\alpha-\tau_{2}^{*}}{\alpha} A_{2 \tau b}^{r}\right)
\end{gathered}
$$

The first term of (54) is positive. Consider $A_{2 \tau}^{r}+\frac{\alpha-\tau_{2}^{*}}{\alpha} A_{2 b}^{r}$ in the second term. By (51) it can 
be written:

$$
A_{2 \tau}^{r}+\frac{\alpha-\tau_{2}^{*}}{\alpha} A_{2 b}^{r}=\omega\left(\tau_{2}^{*}-T^{r}(b)\right)\left(1-\frac{\alpha-\tau_{2}^{*}}{\alpha-\hat{\tau}_{2}^{r}}\right) \geq 0
$$

where the last inequality follows from $\tau_{2}^{*}>\hat{\tau}_{2}^{r}$. Finally, consider $A_{2 \tau \tau}^{p}+A_{2 \tau \tau}^{r}+\frac{\alpha-\tau_{2}^{*}}{\alpha} A_{2 \tau b}^{r}$ in the last term of (54). Taking the second derivatives of (31-32) with respect to $\tau$ and $b$ we have: $A_{2 \tau \tau}^{r}=\omega, A_{2 \tau b}^{r}=-\omega \frac{\alpha}{\alpha-\hat{\tau}_{2}^{r}}$, and $A_{2 \tau \tau}^{p}=\omega\left(\frac{\alpha-\tau_{2}}{\alpha}\right)^{2}+\omega \frac{R_{2}^{p}-V_{2}^{p}}{\alpha}>0$. Hence, this last term can be written:

$$
\omega\left(\frac{\alpha-\tau_{2}^{*}}{\alpha}\right)^{2}+\frac{\omega}{\alpha}\left(R_{2}^{p}-V_{2}^{p}\right)+\omega\left(1-\frac{\alpha-\tau_{2}^{*}}{\alpha-\hat{\tau}_{2}^{r}}\right) \geq 0
$$

The inequality follows form the fact that all the terms in the RHS are positive. This proves inequality (53). Hence, $S_{b}(b)<0$

(iii) The above analysis holds for any $b$ such that $S(b)>0$. Define $\tilde{b}$ such that $S(\tilde{b})=0$ and (33) holds as equality. Since $S(0)>0$, and $S_{b}(b)<0$ while $S(b)>0$, it must be that $\tilde{b}>0$, and the above analysis holds for any $0 \leq b<\tilde{b}$.

(iv) Next, suppose that (33) holds as inequality because the non-negativity constraint on $s_{2}$ binds. Then the equilibrium tax rate $\tau_{2}^{*}=T(b)$ is defined implicitly by the government budget constraint, $T(b)-\frac{T(b)^{2}}{2 \alpha}-b=0$. Implicit differentiation yields:

$$
T_{b}=\frac{\alpha}{\alpha-\tau_{2}^{*}}>0
$$

Differentiating the RHS of the optimality condition (33) with respect to $b$, noting that at $s_{2}=0$ the rich are not aggrieved so that $P_{2 \tau}^{r}=0$, and recalling that $P_{2 b}^{p}=0$ by Lemma 2 , we obtain:

$$
{ }_{-\varsigma} P_{2 \tau \tau}^{p}(T(b), b) T_{b} \leq 0
$$

where the inequality follows from $P_{2 \tau \tau}^{p} \geq 0$ - see the proof that verifies the second order conditions of Proposition 1 - and it is strict if sector $p$ is aggrieved. Hence, as $b$ rises the RHS of (33) falls for a given $\tau_{2}$, making the non-negativity constraint on $s_{2}$ even more binding. Thus, by definition of $\tilde{b}, S(b)=0$ for any $b \geq \tilde{b}$.

(v) Finally, we show that $\tilde{b}<\bar{b}$. By definition, $\bar{b}=\hat{\tau}_{2}^{p}-\frac{\left(\hat{\tau}_{2}^{p}\right)^{2}}{2 \alpha}$. At $\bar{b}$ we have that $A_{2}^{r}=0=A_{2}^{p}$. Hence the RHS of (33) is 0. But the LHS of (33) is strictly positive. Since $\tilde{b}$ is defined by the condition that $S(\tilde{b})=0,(33)$ holds as equality and the RHS of (33) is decreasing in $b$, it must be that $\tilde{b}<\bar{b}$.

Proof. Lemma 3 Consider the poor. By (34) their fair policies maximize the following modified social welfare function

$$
\pi^{p p} \cdot\left[\tau_{1}+\hat{\tau}_{2}^{p}-\tau_{1}^{2} / 2 \alpha-\left(\hat{\tau}_{2}^{p}\right)^{2} / 2 \alpha\right]-\pi^{p r} \cdot\left[\tau_{1}+\hat{\tau}_{2}^{p}\right]
$$


Repeating the steps in the text, subsection 2.4, the value of $\tau_{1}$ that solves this optimization problem is $\hat{\tau}_{1}^{p}=\hat{\tau}^{p}=\frac{2 \delta \alpha}{1+\delta}$. Since the poor's modified welfare function is independent of $b$, their fair value $\hat{b}^{p}$ is indeterminate.

Next consider the rich. Here we have to impose the additional non-negativity constraint $s_{1}=\tau_{1}-F\left(\tau_{1}\right)+b \geq 0$, that was redundant for the poor (the non-negativity constraint on $s_{2}$ is already implicit in the definition of $T^{r}(b)$ ). Let $\gamma^{r}$ denote the Lagrange multiplier on this constraint. By (34) the fair policies for the rich maximize the following Lagrangean with respect to $\tau_{1}$ and $b$ :

$$
-\pi^{r r} \cdot\left[\tau_{1}+T^{r}(b)\right]+\pi^{r p} \cdot\left[\tau_{1}+T^{r}(b)-\tau_{1}^{2} / 2 \alpha-\left(T^{r}(b)\right)^{2} / 2 \alpha\right]+\gamma^{r}\left[\tau_{1}-\tau_{1}^{2} / 2 \alpha+b\right]
$$

The optimality conditions for fair tax rate, $\hat{\tau}_{1}^{r}$, and fair debt, $\hat{b}^{r}$ are, respectively

$$
\begin{aligned}
-(1+\delta)+\left(1-\delta+2 \gamma^{r}\right)\left(1-\tau_{1} / \alpha\right) & \leq 0 \\
-(1+\delta) T_{b}^{r}+(1-\delta) T_{b}^{r}\left(1-T^{r}(b) / \alpha\right)+2 \gamma^{r} & =0
\end{aligned}
$$

where strict inequality in (56) implies $\hat{\tau}_{1}^{r}=0$, and where we used $\pi^{r r}=(1+\delta) / 2, \pi^{r p}=$ $(1-\delta) / 2$. At the point $\hat{b}^{r}=0$, we have $T^{r}(0)=0$ and $T_{b}^{r}=1$ - see footnote 16 . Thus at $\hat{b}^{r}=0$ equation (57) yields $\gamma^{r}=\delta$, which in turn implies that (56) is satisfied as equality at $\hat{\tau}_{1}^{r}=0$. Hence, $\hat{b}^{r}=0$ and $\hat{\tau}_{1}^{r}=0$ solves (56) and (57).

Proof of Lemma 5 Before proving this Lemma, we need the following:

Lemma 5.1 If $\tau_{1} \leq \tau_{2}$ and $b \leq 0$, then in equilibrium $p_{1}^{* p} / p_{2}^{* p}>p_{1}^{* r} / p_{2}^{* r}$.

Proof. By (4), $\frac{p_{1}^{i}}{p_{2}^{i}}=\frac{2 \sigma-A_{2}^{i}}{2 \sigma-A_{1}^{i}}$. By (37-38) and (31-32), if $\tau_{1} \leq \tau_{2}$ and $b \leq 0$, then $A_{1}^{r} \leq 4 A_{2}^{r}$ and $A_{1}^{p} \geq 4 A_{2}^{p}$. Hence,

$$
\frac{p_{1}^{r}}{p_{2}^{r}}=\frac{2 \sigma-A_{2}^{r}}{2 \sigma-A_{1}^{r}} \leq \frac{2 \sigma-A_{2}^{r}}{2 \sigma-4 A_{2}^{r}}
$$

and

$$
\frac{p_{1}^{p}}{p_{2}^{p}}=\frac{2 \sigma-A_{2}^{p}}{2 \sigma-A_{1}^{p}} \geq \frac{2 \sigma-A_{2}^{p}}{2 \sigma-4 A_{2}^{p}}
$$

The RHS of these two expressions are both increasing in $A_{2}^{i}$. Moreover, by Proposition 2 in equilibrium $p_{2}^{* p}>p_{2}^{* r}$, which in turn implies $A_{2}^{p}>A_{2}^{r}$. Thus, $\frac{2 \sigma-A_{2}^{p}}{2 \sigma-4 A_{2}^{p}}>\frac{2 \sigma-A_{2}^{r}}{2 \sigma-4 A_{2}^{r}}$, which together with (58), (59) completes the proof.

Now we can prove Lemma 5

Proof. Lemma 5 Suppose that $b \leq 0$ and the equilibrium tax rates are such that $\tau_{1}^{*} \leq \tau_{2}^{*}$. We show that this leads to a contradiction. In equilibrium $\tau_{1}^{*}$ and $\tau_{2}^{*}$ solve the two first order 
conditions w.r.t. $\tau_{t}$, that we re-write here for convenience:

$$
\begin{aligned}
\tau_{1} & =-\alpha \varsigma\left[P_{1 \tau}^{p}\left(\tau_{1}, b\right)+P_{1 \tau}^{r}\left(\tau_{1}, b\right)\right] \\
\tau_{2} & =-\alpha \varsigma\left[P_{2 \tau}^{p}\left(\tau_{2}, b\right)+P_{2 \tau}^{r}\left(\tau_{2}, b\right)\right]
\end{aligned}
$$

Note that we wrote (61) as equality rather than inequality, because we know from Proposition 3 that $S(b)>0$ for $b<\tilde{b}$. By $(32,38), A_{2 \tau}^{p}=-\omega Z_{2}^{p} \frac{\alpha-\tau_{2}}{\alpha}$ and $A_{1 \tau}^{p}=-\omega\left(Z_{1}^{p}+Z_{2}^{p}\right) \frac{\alpha-\tau_{1}}{\alpha}$ where $Z_{t}^{p} \equiv \hat{\tau}_{t}^{p}-F\left(\hat{\tau}_{t}^{p}\right)-\left(\tau_{t}-F\left(\tau_{t}\right)\right)$. Moreover, by $(31,37) A_{1 \tau}^{r}=\omega\left(Z_{1}^{r}+Z_{2}^{r}\right)$, where $Z_{t}^{r} \equiv \tau_{t}$ for $t=1,2$, and $A_{2 \tau}^{r}=\omega \hat{Z}_{2}^{r}$ where $\hat{Z}_{2}^{r}=\tau_{2}-T^{r}(b)$. By (8) we can then rewrite the two FOCs in (60-61) as:

$$
\begin{aligned}
\tau_{1} & =\frac{\alpha \varsigma \omega}{2(\sigma-\mu)}\left[\left(P_{1}^{p}\right)^{2} \frac{\alpha-\tau_{1}}{\alpha}\left(Z_{1}^{p}+Z_{2}^{p}\right)-\left(P_{1}^{r}\right)^{2}\left(Z_{1}^{r}+Z_{2}^{r}\right)\right]>0 \\
\tau_{2} & =\frac{\alpha \varsigma \omega}{2(\sigma-\mu)}\left[\left(P_{2}^{p}\right)^{2} \frac{\alpha-\tau_{2}}{\alpha} Z_{2}^{p}-\left(P_{2}^{r}\right)^{2} \hat{Z}_{2}^{r}\right]>0
\end{aligned}
$$

Note that for $b \leq 0, \hat{Z}_{2}^{r} \geq Z_{2}^{r}$ since $T^{r}(0)=0$ and $T_{b}^{r}>0$. Rearranging terms, $\tau_{1}^{*}<\tau_{2}^{*}$ then implies:

$$
\left(P_{1}^{p}\right)^{2} Z_{1}^{p} \frac{\alpha-\tau_{1}}{\alpha}-\left(P_{1}^{r}\right)^{2} Z_{1}^{r} \leq Z_{2}^{r}\left[\left(P_{1}^{r}\right)^{2}-\left(P_{2}^{r}\right)^{2}\right]-Z_{2}^{p}\left[\left(P_{1}^{p}\right)^{2} \frac{\alpha-\tau_{1}}{\alpha}-\left(P_{2}^{p}\right)^{2} \frac{\alpha-\tau_{2}}{\alpha}\right]
$$

We now prove the contradiction. Specifically, we show that if $\tau_{1}^{*}<\tau_{2}^{*}$ and $b \leq 0$, then the LHS of the above inequality is positive, while the RHS is negative.

Consider first the RHS, rewriting it as:

$$
\left(P_{2}^{r}\right)^{2} Z_{2}^{r}\left[\frac{\left(P_{1}^{r}\right)^{2}}{\left(P_{2}^{r}\right)^{2}}-1\right]-\left(P_{2}^{p}\right)^{2} Z_{2}^{p}\left[\frac{\left(P_{1}^{p}\right)^{2}}{\left(P_{2}^{p}\right)^{2}} \frac{\alpha-\tau_{1}}{\alpha}-\frac{\alpha-\tau_{2}}{\alpha}\right]
$$

If $\tau_{1}^{*} \leq \tau_{2}^{*}$, then this expression is smaller than

$$
\left(P_{2}^{r}\right)^{2} Z_{2}^{r}\left[\frac{\left(P_{1}^{r}\right)^{2}}{\left(P_{2}^{r}\right)^{2}}-1\right]-\left(P_{2}^{p}\right)^{2} Z_{2}^{p} \frac{\alpha-\tau_{2}}{\alpha}\left[\frac{\left(P_{1}^{p}\right)^{2}}{\left(P_{2}^{p}\right)^{2}}-1\right]
$$

By Lemma 5.1, $P_{1}^{p} / P_{2}^{p}>P_{1}^{r} / P_{2}^{r}$. By (63) and since $\hat{Z}_{2}^{r} \geq Z_{2}^{r},\left(P_{2}^{p}\right)^{2} Z_{2}^{p} \frac{\alpha-\tau_{2}}{\alpha}>\left(P_{2}^{r}\right)^{2} Z_{2}^{r}$. Hence, the expression in (65) is negative, implying that the RHS of (64) is also negative. Next, consider the LHS of (64), re-writing it as

$$
\left(P_{2}^{p}\right)^{2} Z_{1}^{p} \frac{\alpha-\tau_{1}}{\alpha}\left(\frac{P_{1}^{p}}{P_{2}^{p}}\right)^{2}-\left(P_{2}^{r}\right)^{2} Z_{1}^{r}\left(\frac{P_{1}^{r}}{P_{2}^{r}}\right)^{2}
$$


If $\tau_{1}^{*} \leq \tau_{2}^{*}$ then the expression in (66) is smaller than

$$
\left(P_{2}^{p}\right)^{2} Z_{2}^{p} \frac{\alpha-\tau_{2}}{\alpha}\left(\frac{P_{1}^{p}}{P_{2}^{p}}\right)^{2}-\left(P_{2}^{r}\right)^{2} Z_{2}^{r}\left(\frac{P_{1}^{r}}{P_{2}^{r}}\right)^{2}
$$

and if $b \leq 0$ the expression in (67) is larger than

$$
\left(P_{2}^{p}\right)^{2} Z_{2}^{p} \frac{\alpha-\tau_{2}}{\alpha}\left(\frac{P_{1}^{p}}{P_{2}^{p}}\right)^{2}-\left(P_{2}^{r}\right)^{2} \hat{Z}_{2}^{r}\left(\frac{P_{1}^{r}}{P_{2}^{r}}\right)^{2}
$$

By Lemma 5.1, $\frac{P_{1}^{p}}{P_{2}^{p}}>\frac{P_{1}^{r}}{P_{2}^{r}}$. By (63), $\left(P_{2}^{p}\right)^{2} Z_{2}^{p} \frac{\alpha-\tau_{2}}{\alpha}>\left(P_{2}^{r}\right)^{2} \hat{Z}_{2}^{r}$. Thus, the expression in (68) is positive, implying that the LHS of (64) is also positive. Hence a contradiction and inequality (64) cannot hold if $b \leq 0$ and $\tau_{1}^{*} \leq \tau_{2}^{*}$. This proves the Lemma by contradiction.

\section{Proof. Proposition 5}

The proof in the text shows that $b^{*}>0$ and that $\tau_{1}^{*}<\tau_{2}^{*}$ in the range $b^{*}<\tilde{b}$. Here we show that $\tau_{1}^{*}<\tau_{2}^{*}$ also holds if equilibrium debt is in the in the range $b^{*} \geq \tilde{b}$. At $b=\tilde{b}$ the constraint $s_{2} \geq 0$ starts to bind and the partial derivative of the objective function w.r.t $b$ jumps discontinuously. Specifically, for $b>\tilde{b}$ the government is no longer at an interior optimum with regard to $\tau_{2}$ in period 2 , so that $\tau_{2}^{*}=T(b)$ is defined implicitly by the second period budget constraint, $\tau_{2}^{*}-F\left(\tau_{2}^{*}\right)=b$. The optimality condition with respect to $b$ can then be written as:

$$
W_{1 b}+W_{2 \tau} T_{b}-\frac{\varsigma}{2}\left[P_{1 b}^{p}+P_{1 b}^{r}+P_{2 \tau}^{p} T_{b}\right] \leq 0
$$

with strict inequality implying $b^{*}=\tilde{b}$, and where we used the fact that $P_{2 b}^{r}=0$ (because at $s_{2}^{*}=0$ the rich are no longer aggrieved in period 2). Thus, $T_{b}=\frac{\alpha}{\alpha-\tau_{2}}$, while $W_{1 b}=\frac{1}{2}$ and $W_{2 \tau}=-\frac{1}{2}$. Hence $W_{1 b}+W_{2 \tau} T_{b}=-\frac{\tau_{2}}{\alpha-\tau_{2}}$, and in the range $b \geq \tilde{b}$ equation (69) can be rewritten as:

$$
-\frac{\tau_{2}}{\alpha-\tau_{2}}-\varsigma\left[P_{1 b}^{p}\left(\tau_{1}, b\right)+P_{1 b}^{r}\left(\tau_{1}, b\right)+P_{2 \tau}^{p}\left(\tau_{2}, b\right) T_{b}\right] \leq 0
$$

with strict inequality implying $b^{*}=\tilde{b}$.

Repeating the steps in (40-41), using $T_{b}=\frac{\alpha}{\alpha-\tau_{2}}$ and simplifying, we can rewrite (70) as

$$
-\tau_{2}-\varsigma \alpha\left[P_{1 \tau}^{p}+P_{1 \tau}^{r}+P_{1 \tau}^{p} \frac{\tau_{1}-\tau_{2}}{\alpha-\tau_{1}}+P_{2 \tau}^{p}\right] \leq 0
$$

Using (60) and rearranging terms, (71) can be rewritten as:

$$
\tau_{2}-\tau_{1} \geq-\frac{\varsigma \alpha\left(\alpha-\tau_{1}\right) P_{2 \tau}^{p}}{\alpha-\tau_{1}-\varsigma \alpha P_{1 \tau}^{p}}>0
$$

where the inequality follows from $0>P_{t \tau}^{p}$. Hence, $\tau_{2}^{*}>\tau_{1}^{*}$ also in the range $b^{*} \geq \tilde{b}$. 


\section{References}

[1] Acemoglu, Daron and James A. Robinson 2006a. Economic Origins of Dictatorship and Democracy. New York: Cambridge University Press.

[2] Acemoglu, Daron and James A. Robinson 2006b. "De Facto Political Power and Institutional Persistence." American Economic Association Papers and Proceedings 96(2): 325-330.

[3] Alesina, Alberto, Dorian Carloni and Giampaolo Lecce 2012. "The Electoral Consequences of Large Fiscal Adjustments." in Fiscal Policy after the Financial Crisis. Cambridge, MA: National Bureau of Economic Research Inc.

[4] Alesina, Alberto and Guido Tabellini 1990. "A Positive Theory of Fiscal Deficits and Government Debt." Review of Economic Studies 57 no. 3: 403-414.

[5] Akerlof, George 1982. "Labor Contracts as Partial Gift Exchange." Quarterly Journal of Economics (November) Vol XCVII N.4: 543-569.

[6] Akerlof, Robert 2012. "Anger and Compliance." Manuscript, University of Warwick.

[7] Babcock, Linda, George Loewenstein, Samuel Issacharoff and Colin Camerer 1995. "Biased Judgments of Fairness in Bargaining." American Economic Review 85(5): 1337-1343.

[8] Banks, Arthur S. and Kenneth A. Wilson 2012. "Cross-National Time-Series Data Archive." Databanks International, Jerusalem, Israel. http://www.databanksinternational.com.

[9] Bates, Robert H. 1981. Markets and States in Tropical Africa: The Political Basis of Agricultural Policies. Berkeley: University of California Press.

[10] Battaglini, Marco and Roland Bénabou 2003. "Trust, Coordination, and the Industrial Organization of Political Activism." Journal of the European Economic Association 1(4): 851-889.

[11] Battigalli, Pierpaolo and Martin Dufwenberg 2009. "Dynamic Psychological Games." Journal of Economic Theory 144(1): 1-35.

[12] Battigalli, Pierpaolo, Martin Dufwenberg and Alec Smith 2015. "Frustration and Anger in Games." Manuscript, IGIER, Bocconi University.

[13] Bénabou, Roland and Jean Tirole 2009. "Over My Dead Body: Bargaining and the Price of Dignity." American Economic Review 99(2): 459-465. 
[14] Berkowitz Leonard and Eddie Harmon-Jones 2004. "Toward an Understanding of the Determinants of Anger." Emotion 4(2): 107-130.

[15] Brunnermeier, Markus K. and Jonathan A. Parker 2005. "Optimal Expectations." American Economic Review 95(4): 1092-1118.

[16] Collins, William J. and Robert A. Margo 2007. "The Economic Aftermath of the 1960s Riots in American Cities: Evidence from Property Values." Journal of Economic History 67(04): 849-883.

[17] Diermeier, Daniel 2012. Formal Behavioralism. Cambridge University Press. forthcoming.

[18] DiPasquale, Denise and Edward L. Glaeser 1999. "Incentives and Social Capital: Are Homeowners Better Citizens?." Journal of Urban Economics Vol. 45 no. 2: 354-384.

[19] Fehr, Ernst, Oliver Hart and Christian Zehnder 2011. "Contracts as Reference PointsExperimental Evidence." American Economic Review 101(2): 493-525.

[20] Francisco, Ronald A. 2006. European Protest and Coercion Data, 1980 through 1995, University of Kansas. http://web.ku.edu/ ronfran/data/index.html.

[21] Geanakoplos, John, David Pearce and Ennio Stacchetti 1989. "Psychological Games and Sequential Rationality." Games and Economic Behavior 1: 60-79.

[22] Granovetter, Mark 1978. "Threshold Models of Collective Behavior." American Journal of Sociology 83(6): 1420-1443.

[23] Hart, Oliver and John Moore 2008. "Contracts as Reference Points." Quarterly Journal of Economics 123(1): 1-48.

[24] Hastorf, Albert and Hadley Cantril 1954. "They Saw a Game: A Case Study." Journal of Abnormal and Social Psychology 49(1): 129-134.

[25] Herweg, Fabian and Klaus Schmidt 2014. "Loss Aversion and Ex Post Inefficient Renegotiation." The Review of Economic Studies 1: 1-38.

[26] Koszegi, Botond and Matthew Rabin 2006. "A Model of Reference-Dependent Preferences." Quarterly Journal of Economics 121(4): 1133-1165.

[27] Lohmann, Susanne 1993. "A Signaling Model of Informative and Manipulative Political Action." The American Political Science Review Vol. 87 No. 2: 319-333

[28] Messick, David and Keith, Sentis 1979. "Fairness and Preference." Journal of Experimental Social Psychology 15(4): 418-434. 
[29] Olson, Mancur 1965. The Logic of Collective Action. Cambridge, MA: Harvard University Press.

[30] Persson, Torsten and Guido Tabellini 2000. Political Economics: Explaining Economic Policy. Cambridge, MA: MIT Press.

[31] Persson, Torsten and Guido Tabellini 2009. "Democratic Capital: The Nexus of Political and Economic Change." American Economic Journal: Macroeconomics 1(2): 88-126.

[32] Ponticelli, Jacopo and Hans-Joachim Voth 2011. "Austerity and Anarchy: Budget Cuts and Social Unrest in Europe, 1919-2009." CEPR Discussion Paper No. DP8513.

[33] Rabin, Matthew 1995. "Moral preferences, Moral Constraints and Self-serving Biases." Manuscript, Department of Economics, University of California, Berkeley.

[34] Rotemberg, Julio J. 2010. "Altruistic Dynamic Pricing with Customer Regret." Scandinavian Journal of Economics 112(4): 646-672.

[35] Reinhart, Carmen and Kenneth Rogoff 2011b. "From Financial Crash to Debt Crisis." American Economic Review 101(5): 1676-1706.

[36] Shalev, Jonathan 2000. "Loss Aversion Equilibrium." International Journal of Game Theory 29(2): 269-287.

[37] Scholzman, Kay Lehman and Sidney Verba 1979. Injury to Insult. Cambridge, MA: Harvard University Press.

[38] Sugden, Robert 2003. "Reference-dependent Subjective Expected Utility." Journal of Economic Theory 111(2): 172-191.

[39] Tabellini, Guido 2008. "The Scope of Cooperation: Values and Incentives." Quarterly Journal of Economics 123(3): 905-950.

[40] Tullock, Gordon 1971. "The Paradox of Revolution." Public Choice Vol. 11: 89-99.

[41] Voth, Hans-Joachim 2011. "Tightening Tensions: Fiscal Policy and Civil Unrest in Eleven South American Countries, 1937-1995." in J. Gal (ed), Fiscal Policy and Macroeconomic Performance. Santiago de Chile: Central Bank of Chile.

[42] Woo, Jaejoon 2003. "Economic, Political, and Institutional Determinants of Public Deficits." Journal of Public Economics 87(3-4): 387-426. 
Table 1: Who Participates in Riots

\begin{tabular}{|c|c|c|c|}
\hline \multirow[t]{2}{*}{ Dependent variable } & \multicolumn{3}{|c|}{ Recent participation in lawful demonstrations } \\
\hline & (1) & $(2)$ & $(3)$ \\
\hline Primary education & $\begin{array}{r}-0.054^{* * *} \\
(0.006)\end{array}$ & $\begin{array}{r}-0.051^{* * *} \\
(0.006)\end{array}$ & $\begin{array}{r}-0.015^{* * *} \\
(0.003)\end{array}$ \\
\hline Tertiary education & $\begin{array}{r}0.062^{* * *} \\
(0.006)\end{array}$ & $\begin{array}{r}0.063^{* * *} \\
(0.006)\end{array}$ & $\begin{array}{r}0.020^{* * *} \\
(0.002)\end{array}$ \\
\hline Age 30 or below & $\begin{array}{r}0.011 \\
(0.007)\end{array}$ & $\begin{array}{r}0.009 \\
(0.007)\end{array}$ & $\begin{array}{r}0.012^{* * *} \\
(0.003)\end{array}$ \\
\hline Age 50 or below & $\begin{array}{r}-0.015^{* *} \\
(0.006)\end{array}$ & $\begin{array}{r}-0.015^{* *} \\
(0.006)\end{array}$ & $\begin{array}{r}-0.008^{* * *} \\
(0.002)\end{array}$ \\
\hline Male & $\begin{array}{r}0.035^{* * *} \\
(0.005)\end{array}$ & $\begin{array}{r}0.029^{* * *} \\
(0.005)\end{array}$ & $\begin{array}{r}0.006^{* *} \\
(0.002)\end{array}$ \\
\hline Unemployed & $\begin{array}{r}0.061^{* * *} \\
(0.009)\end{array}$ & $\begin{array}{r}0.058^{* * *} \\
(0.009)\end{array}$ & $\begin{array}{r}0.014^{* * *} \\
(0.002)\end{array}$ \\
\hline Worker & $\begin{array}{r}0.046^{* * *} \\
(0.007)\end{array}$ & $\begin{array}{r}0.046^{* * *} \\
(0.007)\end{array}$ & $\begin{array}{r}0.015^{* * *} \\
(0.002)\end{array}$ \\
\hline Student & $\begin{array}{r}0.096^{* * *} \\
(0.011)\end{array}$ & $\begin{array}{r}0.094^{* * *} \\
(0.011)\end{array}$ & $\begin{array}{r}0.032^{* * *} \\
(0.003)\end{array}$ \\
\hline Income below 30 percentile & $\begin{array}{r}0.014^{* * *} \\
(0.006)\end{array}$ & $\begin{array}{r}0.016^{* * *} \\
(0.006)\end{array}$ & \\
\hline Income above 70 percentile & $\begin{array}{r}-0.014^{* *} \\
(0.007)\end{array}$ & $\begin{array}{r}-0.014^{* *} \\
(0.007)\end{array}$ & \\
\hline Children at home & $\begin{array}{r}-0.005 \\
(0.006)\end{array}$ & $\begin{array}{r}-0.008 \\
(0.006)\end{array}$ & $\begin{array}{r}-0.001 \\
(0.002)\end{array}$ \\
\hline Satisfied with life & $\begin{array}{r}-0.005^{* * *} \\
(0.001)\end{array}$ & $\begin{array}{r}-0.005^{* * *} \\
(0.001)\end{array}$ & $\begin{array}{r}0.000 \\
(0.000)\end{array}$ \\
\hline Confidence/satisfaction with government & $\begin{array}{r}-0.009^{* * *} \\
(0.003)\end{array}$ & $\begin{array}{r}-0.015^{* * *} \\
(0.003)\end{array}$ & $\begin{array}{r}-0.002^{* * *}(0.001)\end{array}$ \\
\hline Satisfaction with economy & & & $\begin{array}{r}0.000 \\
(0.000)\end{array}$ \\
\hline Satisfaction with democracy & & & $\begin{array}{r}-0.000 \\
(0.001)\end{array}$ \\
\hline State of health services & & & $\begin{array}{r}-0.000 \\
(0.000)\end{array}$ \\
\hline State of education & & & $\begin{array}{r}-0.002^{* * *} \\
(0.000)\end{array}$ \\
\hline Discriminated group & & & $\begin{array}{r}0.029^{* * *} \\
(0.003)\end{array}$ \\
\hline Autonomy Index & $\begin{array}{c}-0.004^{*} \\
(0.002)\end{array}$ & $\begin{array}{r}-0.002 \\
(0.002)\end{array}$ & \\
\hline Income should be made more equal & $\begin{array}{r}0.001 \\
(0.001)\end{array}$ & $\begin{array}{r}0.001 \\
(0.001)\end{array}$ & $\begin{array}{r}0.006^{* * *} \\
(0.001)\end{array}$ \\
\hline Extreme LEFT on political scale & $\begin{array}{r}0.101^{* * *} \\
(0.006)\end{array}$ & $\begin{array}{r}0.094^{* * *} \\
(0.006)\end{array}$ & $\begin{array}{r}0.026^{* * *} \\
(0.003)\end{array}$ \\
\hline Extreme RIGHT on political scale & $\begin{array}{r}0.038^{* * *} \\
(0.006)\end{array}$ & $\begin{array}{r}0.030^{* * *} \\
(0.006)\end{array}$ & $\begin{array}{r}-0.005 \\
(0.005)\end{array}$ \\
\hline Voted parliament/national elections & $\begin{array}{r}0.054^{* * *} \\
(0.006)\end{array}$ & $\begin{array}{r}0.049^{* * *} \\
(0.006)\end{array}$ & $\begin{array}{r}0.011^{* * *} \\
(0.002)\end{array}$ \\
\hline Don't know for which party I will vote for & $\begin{array}{r}-0.016^{* *} \\
(0.006)\end{array}$ & $\begin{array}{r}-0.009 \\
(0.006)\end{array}$ & \\
\hline Involved in a political party & & $\begin{array}{r}0.119^{* * *} \\
(0.006)\end{array}$ & $\begin{array}{r}0.053^{* * *} \\
(0.004)\end{array}$ \\
\hline Pct of involvement in a political party & & & $\begin{array}{r}0.071^{* * *} * \\
(0.007)\end{array}$ \\
\hline Feel closer to a particular party & & & $\begin{array}{r}0.015^{* * *} \\
(0.002)\end{array}$ \\
\hline Observations & 28,799 & 28,537 & 136,087 \\
\hline Survey & WVS & WVS & ESS \\
\hline Pseudo R-squared & 0.0928 & 0.108 & 0.195 \\
\hline
\end{tabular}

NOTE. - The dependent variable is a dummy defined as follows:

ESS: 1 if "Taken part into lawful public demonstrations on the last 12 months";

WVS: 1 if "Political action recently done: attending peaceful/lawful demonstration".

Probit estimations - Marginal effects reported. Wave and Country Fixed effect included.

Robust standard errors in parentheses. ${ }^{* * *} \mathrm{p}<0.01,{ }^{* *} \mathrm{p}<0.05,{ }^{*} \mathrm{p}<0.1$. 


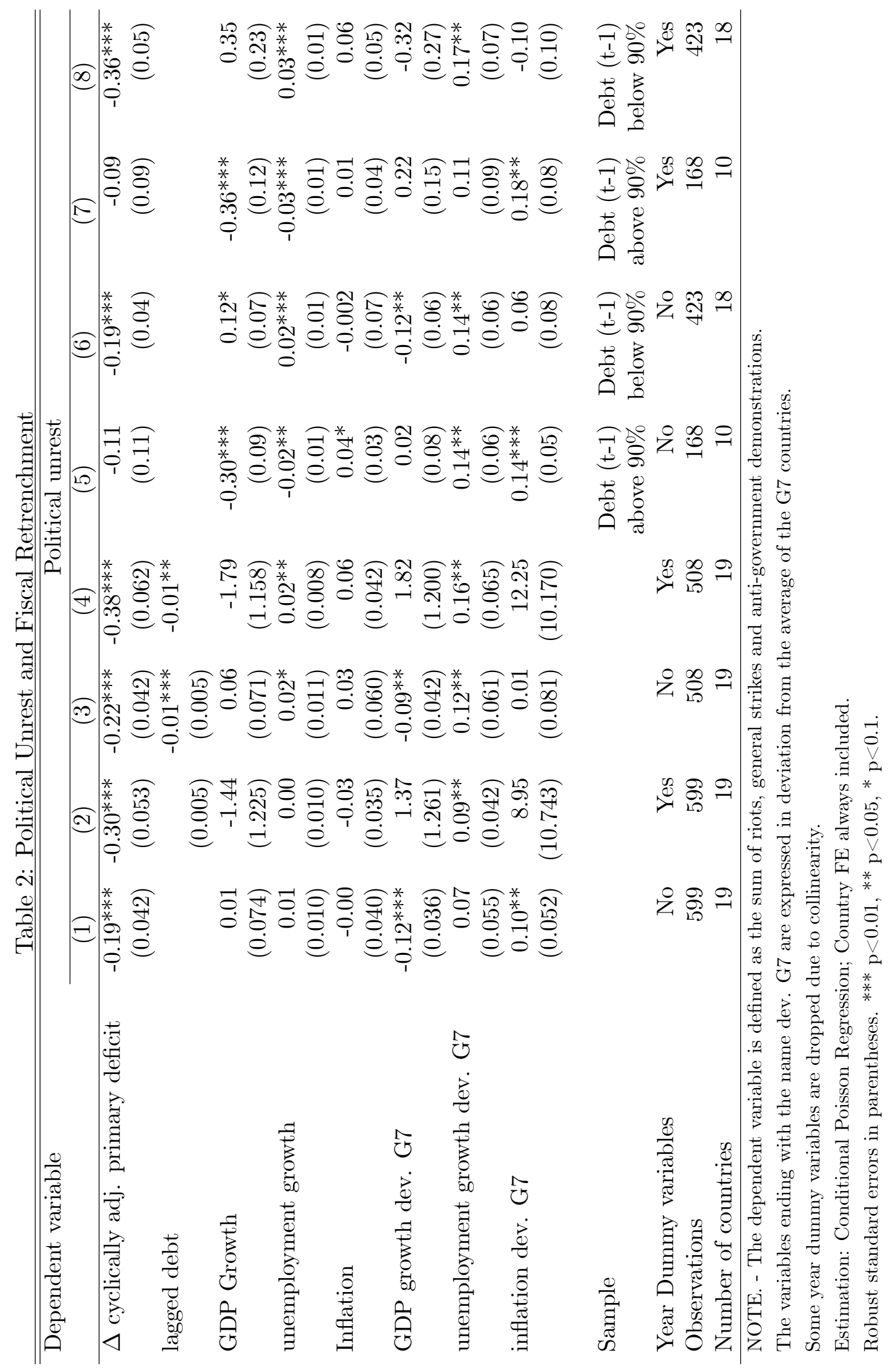




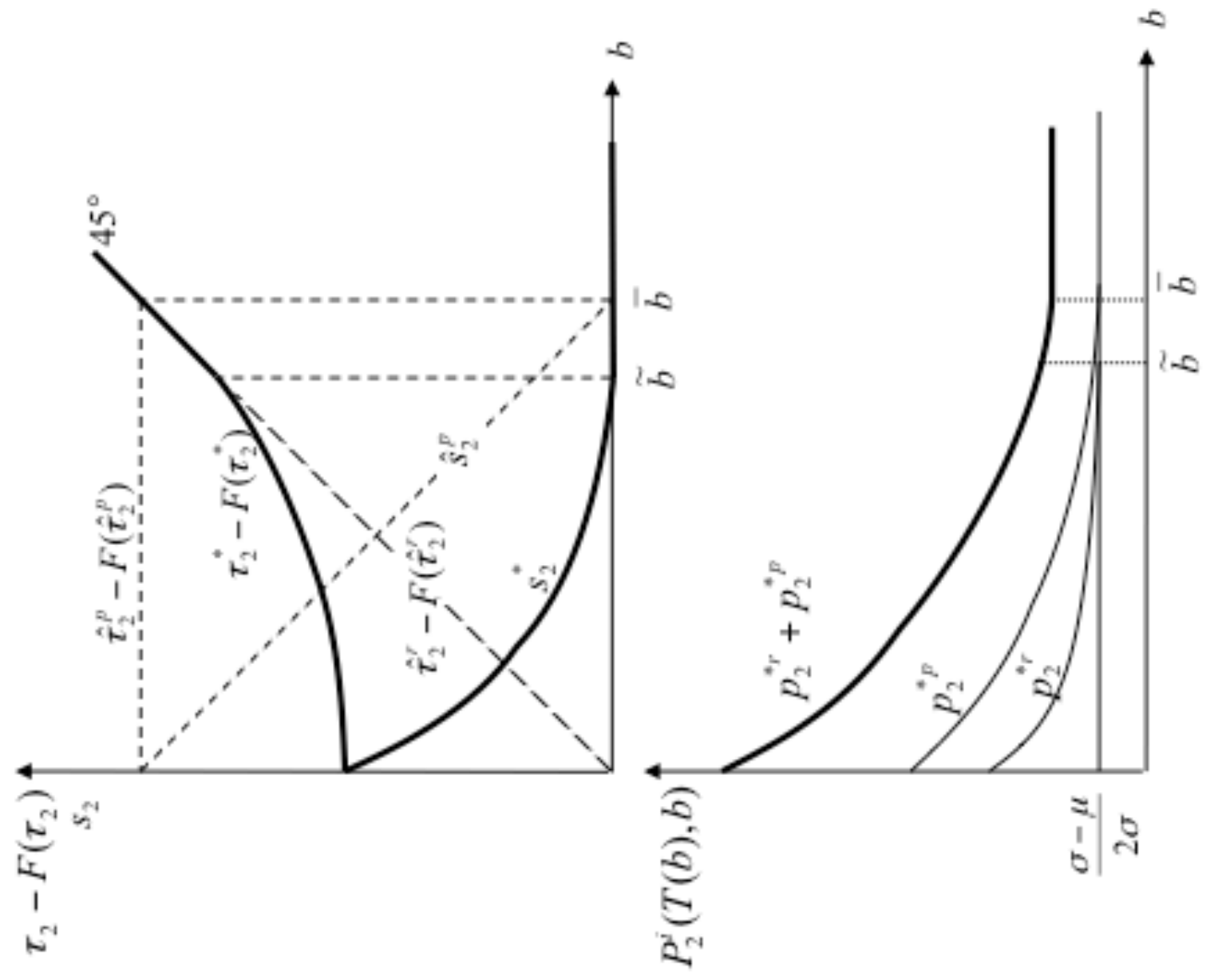

